\title{
Scutellarein inhibits the development of colon cancer via CDC4-mediated RAGE ubiquitination
}

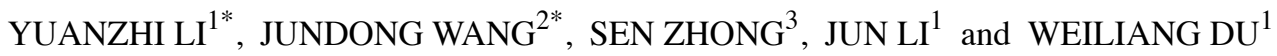 \\ ${ }^{1}$ Traditional Chinese Medicine Department, The Affiliated Hospital of Southwest Medical University, Luzhou, \\ Sichuan 646000; Departments of ${ }^{2}$ Gastroenterology and ${ }^{3}$ Infection, Hospital of Chengdu University \\ of Traditional Chinese Medicine, Chengdu, Sichuan 610000, P.R. China
}

Received July 3, 2019; Accepted January 13, 2020

DOI: $10.3892 / \mathrm{ijmm} .2020 .4496$

\begin{abstract}
Scutellarein has been identified to serve an anti-tumor function in human colon cancer, but the underlying mechanisms remain largely unclear. The present study further investigated the effect and mechanism of scutellarein, extracted from wild chrysanthemum, in the progression of colon cancer. MTT, clone formation, flow cytometry and tumor-bearing mice assays were used to detect cell viability, clone formation, apoptosis and tumorigenesis, respectively. Western blot and quantitative PCR assays were performed for protein and mRNA expression detection. The results revealed that, compared with the control group, scutellarein treatment significantly inhibited the viability and induced the apoptosis of colon cancer cells $(\mathrm{P}<0.05)$, with significant decreases in receptor for advanced glycosylation end products (RAGE) protein expression and stability and an increase in RAGE ubiquitination $(\mathrm{P}<0.05)$. However, the effects of scutellarein exerted in cell apoptosis and viability were rescued by RAGE overexpression, and accelerated by RAGE knockdown. Additionally, it was observed that scutellarein treatment induced a significant increase in the expression of cell division control protein 4 (CDC4) compared with the control group $(\mathrm{P}<0.05)$, which was then verified to interact with RAGE protein and mediate its ubiquitination. Overexpression of CDC4 inhibited colon cancer cell viability and promoted the apoptosis of SW480 and T84 cells, whereas this function was weakened when RAGE was overexpressed. Furthermore, CDC4 downregulation significantly neutralized scutellarein functions in promoting cell apoptosis and inhibiting cell
\end{abstract}

Correspondence to: Dr Yuanzhi Li, Traditional Chinese Medicine Department, The Affiliated Hospital of Southwest Medical University, 25 Taiping Street, Luzhou, Sichuan 646000, P.R. China

E-mail: yuanzhili5945@163.com

\section{*Contributed equally}

Key words: scutellarein, wild chrysanthemum, colon cancer, cell division control protein 4 , receptor for advanced glycosylation end products, ubiquitination viability and tumorigenesis in colon cancer cells compared with the scutellarein group $(\mathrm{P}<0.05)$. In conclusion, the present study revealed that scutellarein inhibited the development of colon cancer through upregulating CDC4-mediated RAGE ubiquitination.

\section{Introduction}

Colon cancer is one of the most common malignant alimentary canal tumor types, and mainly occurs on the joint of the rectum and colon sigmoideum (1). A total of 1.2 million patients are diagnosed annually and $\sim 0.6$ million mortalities occur each year globally (1). Nearly $60 \%$ patients with colon cancer will develop metastasis, which results in a high mortality of patients with colon cancer $(2,3)$. Colon cancer is the fifth highest cause of cancer-associated mortalities in China, and the morbidity continues to rapidly rise, with a 5-year survival rate of $40-60 \%$ (4). Therefore, it is important to further reveal the underlying mechanisms of colon cancer.

An increasing number of herbs have been used in medicines and cosmetics for centuries. Among them, wild chrysanthemum (Chrysanthemum indicum L.) has a range of biological activities. In China, wild chrysanthemum is used to cure numerous types of inflammatory diseases (5). Studies have documented that flavonoids are the active ingredients in wild chrysanthemum, including hispidulin, isorhoifolin and scutellarein (6-8). Scutellarein, a flavone present in the perennial herb Scutellaria baicalensis, is the aglycone of scutellarin with a free hydroxyl in 7 position, and exerts a higher bioavailability compared with scutellarin (9). A variety of studies have demonstrated that scutellarein may inhibit the viability of human lung cancer cells and fibrosarcoma cells (9-11), in addition to serving an anti-tumor function in human colon cancer $(12,13)$. However, the underlying mechanisms of scutellarin, derived from the wild chrysanthemum, in the repression of colon cancer progression remain largely unknown.

Cluster of differentiation (CD) family proteins, including CD44, CD50 and CD74, are all members of the immunoglobulin superfamily, and are associated with cancer cell migration and immune response $(14,15)$. Melanoma cell adhesion molecule (MCAM), also known as CD146, is a cell adhesion molecule and is involved in several cellular processes, including cell invasion, migration, immune response and 
signal transduction (16). The increased expression of MCAM in the primary tumor types is associated with metastasis and prognosis in several cancer types (16-18). Mucosal addressin cell adhesion molecule 1 (Madcam1) is known as a type of adhesion molecule, which is involved in inflammatory responses with no expression in the majority of normal tissues $(19,20)$. Receptor for advanced glycation end products (RAGE) is a signal transduction receptor that is involved in multiple pathologic conditions, including carcinogenesis and inflammation relying on its diverse ligands $(21,22)$. It is well acknowledged that RAGE expression is associated with multifarious cancer types, including colon cancer (23). These results suggest that all of the aforementioned proteins serve a function in carcinogenesis. However, whether scutellarein inhibits the development of colon cancer through modulating these oncoproteins (CD44, CD50, CD74, CD138, MCAM, CD151, CD166, CD206, RAGE and Madcam1) is not yet known.

Ubiquitylation is considered to be an important modification of nuclear and cytoplasmic proteins at the post-translational level, as it is known that ubiquitylation serves an important function in cell apoptosis, cell cycle and DNA damage repair $(24,25)$. A number of studies have demonstrated that ubiquitylation is strongly associated with the initiation and progression of carcinogenesis $(26,27)$. Notably, numerous ubiquitin-associated proteins have been revealed as tumor suppressors/oncogenes and therapeutic targets in different tumor types $(28,29)$. However, whether ubiquitylation is involved in scutellarein-mediated colon cancer repression remains unknown.

The present study aimed to investigate the function of scutellarein in ubiquitylation, and to determine the expression of a number of ubiquitin-associated proteins in the presence of scutellarein. In order to elucidate the functions of scutellarein for the potential treatment of colon cancer, the anticancer function of scutellarein from wild chrysanthemum in the development of colon cancer cells and its associated mechanisms were examined.

\section{Materials and methods}

Extraction of scutellarein. A whole plant of wild chrysanthemum was gathered from the wild, dried in the air and then ground, followed by extraction using $99.5 \%$ ethanol three times. Subsequently, the ethanol was removed and the extract was suspended in water and partitioned with petroleum ether and acetyl acetate. Under reduced pressure, the acetyl acetate was evaporated and obtained. This was handled with column chromatography on silica gel eluted with gradient dichloromethane and purified by Sephadex LH-20 to obtain a yellow powder. The structure of the compound was determined using $1 \mathrm{H}$ and $13 \mathrm{C}$ nuclear magnetic resonance (NMR) spectra and electrospray ionization mass spectrometry analysis. The results revealed the peaks to be at $\mathrm{m} / \mathrm{z} 287\left[\mathrm{M}^{+} \mathrm{H}\right]^{+}$and $285\left[\mathrm{M}^{-} \mathrm{H}\right]^{-}$, demonstrating that the molecular weight was $286 \mathrm{~g} / \mathrm{mol}$. On the other hand, two single peaks at $\delta 6.77(1 \mathrm{H}, \mathrm{s})$ and $6.57(1 \mathrm{H}, \mathrm{s})$ were observed on the 1H NMR spectrum. Furthermore, on the 13C NMR spectrum, 13 carbon signals were detected. The purity of the scutellarein was identified by using high performance liquid chromatography on an Agilent 1,100 high performance liquid chromatography system (Agilent Technologies, Inc.), and was determined to be $96.5 \%$. The chromatographic column was Waters Xterra Rp- $\mathrm{C}_{18}(3.0 \times 100 \mathrm{~mm} ; 3.5 \mu \mathrm{m})$, the mobile phase A was acetonitrile solution, and the mobile phase B was $0.1 \%$ formic acid water. The gradient elution conditions were $10-20 \%$ A (0-10 min), 20-25\% A (10-30 min) and 25-45\% A (30-60 min), and the volume flow rate was $0.4 \mathrm{ml} / \mathrm{min}$ with a column temperature of $20^{\circ} \mathrm{C}$ and an injection volume of $5 \mu 1$. The UV detection wavelength was $275 \mathrm{~nm}$, and the running time was $60 \mathrm{~min}$.

Cell culture. Colon cell lines CL-40, SW480 and T84 were all obtained from the American Type Culture Collection. T84 cells were maintained in high glucose-DMEM medium (Gibco; Thermo Fisher Scientific, Inc.) with the presence of $10 \%$ fetal bovine serum (FBS; Biological Industries) and 1\% (v/v) penicillin-streptomycin, while SW480 cells were cultured in DMEM/F-12 medium (Gibco; Thermo Fisher Scientific, Inc.) supplemented with $10 \%$ FBS and $1 \%$ penicillin-streptomycin, and CL-40 cells were incubated with RPMI-1640 medium (Gibco; Thermo Fisher Scientific, Inc.) supplemented with $10 \%$ FBS and $1 \%$ penicillin-streptomycin. All cells were maintained in a humidified condition of $5 \% \mathrm{CO}_{2}$ at $37^{\circ} \mathrm{C}$.

MTT analysis. MTT analysis was performed to investigate the half maximal inhibitory concentration $\left(\mathrm{IC}_{50}\right)$ of scutellarein in colon cancer cells and cell viability. SW480 and T84 cells (3,000 cells/well) were cultured in 96-well plates for $24 \mathrm{~h}$ following adherence, and were then exposed to scutellarein at a gradient concentration for $36 \mathrm{~h}$. Subsequently, $10 \mu \mathrm{l}$ MTT solution (Beyotime Institute of Biotechnology) were added per well and the cells were incubated for another $4 \mathrm{~h}$ at $37^{\circ} \mathrm{C}$. DMSO was used to dissolve the purple formazan. Then, the optical density (OD) values were measured at $570 \mathrm{~nm}$, and the $\mathrm{IC}_{50}$ value was calculated. In addition, cell viability was also detected using MTT. Cells were cultured in 96-well plates, and underwent different treatments, including scutellarein, scutellarein+RAGE overexpression (OE-RAGE), scutellarein+RAGE short hairpin RNA (sh-RAGE), OE-CDC4, OE-CDC4+OE-RAGE, following adherence. Following incubation at $37^{\circ} \mathrm{C}$ for $1,2,3,4$ and 5 days, the cells were treated with MTT solution for $4 \mathrm{~h}$, and the OD values were measured at $570 \mathrm{~nm}$.

Western blot analysis. The colon cancer SW480 and T84 cells were seeded into 6-well plates and cultured for $12 \mathrm{~h}$ until adherence. Then, cells underwent different treatments (scutellarein, scutellarein+OE-RAGE, scutellarein+sh-RAGE, OE-CDC4 and OE-CDC4+OE-RAGE) for $48 \mathrm{~h}$, and then the cells were gathered. The total protein was isolated using RIPAIII (Beijing Solarbio Science \& Technology Co., Ltd.) and centrifuged at $12,000 \mathrm{x} \mathrm{g}$ at $4^{\circ} \mathrm{C}$ for $20 \mathrm{~min}$. Proteins from supernatants were quantified using bicinchoninic acid analysis (EMD Millipore) and boiled with 1x loading buffer. A total of $20 \mathrm{mg}$ protein was separated using $10 \%$ SDS-PAGE, and was subsequently transferred onto polyvinylidene fluoride membranes (EMD Millipore). The membranes were immersed into 5\% non-fat milk for $1 \mathrm{~h}$ at room temperature to block, following by being washed with TBS with $0.1 \%$ $(\mathrm{v} / \mathrm{v})$ Tween-20 a total of 3 times. Then, the membranes were incubated with primary antibodies at $4^{\circ} \mathrm{C}$ overnight. Next 
day, the membranes were incubated with the corresponding horseradish peroxidase (HRP)-conjugated anti-mouse (cat. no. 7076) or anti-rabbit (cat. no. 7074) secondary antibody (1:10,000 dilution; Cell Signaling Technology, Inc.) at room temperature for $2 \mathrm{~h}$. Subsequently, the complexes were tested using the electrochemical luminescence of horseradish peroxidase substrate (EMD Millipore) and analyzed using ImageJ software (version 1.48; National Institutes of Health). The primary antibodies were as follows: Anti-CD44 (1:1,000; cat. no. \#3578), anti-ring finger and $\mathrm{CHY}$ zinc finger domain containing 1 (RCHY1; 1:1,000; cat. no. \#5754), anti-cleaved caspase3 (1:1,000; cat. no. \#9661), anti-caspase3 (1:1,000; cat. no. \#9662), anti-cleaved caspase7 (1:1,000; cat. no. \#9492), anti-caspase7 (1:1,000, no. \#9491), anti-phosphorylated (p-) p65 (1:1,000; cat. no. \#3033), anti-p65 (1:1,000; cat no. \#8242) and anti-protein kinase C (PKC; 1:1,000; cat. no. \#2056) antibodies were all obtained from Cell Signaling Technology, Inc. Anti-RAGE (1:1,000; cat. no. sc365154), anti-cell division control protein 4 (CDC4; 1:1,000; cat. no. sc293423), anti-CD50 (1:1,000; cat. no. sc71307), anti-CD74 (1:1,000; cat. no. sc166047), anti-CD138 (1:1,000; cat. no. sc390791), anti-CD151 (1:1,000; cat. no. sc271216), anti-CD166 (1:1,000; cat. no. sc74558), anti-CD206 (1:1,000; cat. no. sc70586), anti-MCAM (1:1,000; cat. no. sc376762), anti-Madcam1 (1:1,000; cat. no. sc374398), anti-Cbl proto-oncogene (CBL; 1:1,000; cat. no. sc1651), anti-Ubiquitin (1:1,000; cat. no. sc166553), anti-SMAD specific ubiquitin protein ligase 1 (Smurf1; 1:1,000; cat. no. sc100616), anti-MDM2 proto-oncogene (MDM2; 1:1,000; cat. no. sc5304) and anti-GAPDH (1:1,000; cat. no. sc47724) were all purchased from Santa Cruz Biotechnology, Inc., and anti-vascular endothelial growth factor (VEGF; 1:1,000; cat. no. ab46154) was purchased from Abcam. The corresponding secondary antibodies were obtained from OriGene Technologies, Inc.

Cycloheximide (CHX) analysis. The colon cancer SW480 and T84 cells were routinely cultured and underwent different treatments. Then, the cells were treated with $\mathrm{CHX}(100 \mu \mathrm{g} / \mathrm{ml})$ for $1,2,4,8$ and $24 \mathrm{~h}$ at $37^{\circ} \mathrm{C}$, following which the total protein was extracted.

Colony formation assay. Colon cancer SW480 and T84 cells (1,000 cells/dish) were seeded in $3.5 \mathrm{~cm}$ dishes and cultured in a humidified environment with $5 \% \mathrm{CO}_{2}$ at $37^{\circ} \mathrm{C}$ for $24 \mathrm{~h}$. Then, different concentrations of scutellarein $(10,20,40,60$ and $80 \mu \mathrm{M}$ ) were added into each dish and the cells were incubated with scutellarein at $37^{\circ} \mathrm{C}$ for 15 days. Cells treated with DMSO were used as the negative control. Subsequent to the incubation at $37^{\circ} \mathrm{C}$ for 15 days, the cells were washed with phosphate buffered saline (PBS) 3 times, following by staining with $1 \mathrm{ml}$ crystal violet solution for $10 \mathrm{~min}$ at room temperature. The cells were then washed with PBS prior to the colonies being counted.

Reverse transcription-quantitative PCR (RT-qPCR). Colon cancer SW480 and T84 cells with different treatments were obtained and mRNA was extracted using TRIzol ${ }^{\circledR}$ reagent (Invitrogen; Thermo Fisher Scientific, Inc.) according to the manufacturer's protocols. Subsequently, reverse transcription $\left(42^{\circ} \mathrm{C}\right.$ for $30 \mathrm{~min}$ followed by $85^{\circ} \mathrm{C}$ for $5 \mathrm{~min}$ ) was performed using EasyScript Reverse Transcriptase (Beijing Transgen Biotech Co., Ltd.) followed by qPCR on a DA7600 Real-time Nucleic Acid Amplification Fluorescence Detection System (Bio-Rad Laboratories, Inc.) in a $25 \mu \mathrm{l}$ volume system using the TransStart Green qPCR SuperMix (Beijing Transgen Biotech Co., Ltd.). The thermocycling conditions were as follows: Initial denaturation for $3 \mathrm{~min}$ at $95^{\circ} \mathrm{C}$, followed by 35 cycles of denaturation at $95^{\circ} \mathrm{C}$ for $10 \mathrm{sec}$ and annealing/extension at $55^{\circ} \mathrm{C}$ for $30 \mathrm{sec}$.

The primers were obtained from Sangon Biotech Co., Ltd. Melting-curve analysis was conducted to recognize the reaction specificity. All experiments were performed in triplicate and the data were analyzed using the $2^{-\Delta \Delta \mathrm{Cq}}$ method (30). Primers of RAGE, CDC4 and $\beta$-catenin were as follows: RAGE forward, 5'-GGGGTACCAAGGAAGCAGGTAGGC AGCC-3' and reverse, 5'-CCGCTCGAATCCATTCCTGTT CATCTGC-3'; CDC4 forward, 5'-GTGGGACATACAGGT GGA-3' and reverse, 5'-CAACGCACAGTGGAACTA-3'; $\beta$-actin forward, 5'-CATGTACGTTGCTATCCAGGC-3' and reverse, 5'-CTCCTTAATGTCACGCACGAT-3'.

Immunoprecipitation (IP). An IP assay was performed using protein $\mathrm{G}$ plus A-agarose beads as established, with $\mathrm{CDC} 4$ or RAGE antibodies obtained from Santa Cruz Biotechnology, Inc. In brief, SW480 and T84 cells were first rinsed with cold PBS and lysed in IP lysis buffer (Thermo Fisher Scientific, Inc.); the total proteins were obtained after being centrifuged at $20,000 \mathrm{x}$ g for $30 \mathrm{~min}$ at $4^{\circ} \mathrm{C}$ and served as the 'Input' sample. Then, the cell lysate containing $200 \mu \mathrm{g}$ protein was incubated with Dynabeads ${ }^{\circledR}$ protein G (Thermo Fisher Scientific, Inc.) for $1 \mathrm{~h}$ at room temperature, and incubated with $2 \mu \mathrm{g}$ of antibody against RAGE (cat. no. sc365154; Santa Cruz Biotechnology, Inc.) or IgG (cat. no. 5946, Cell Signaling Technology, Inc.; negative control) overnight at $4^{\circ} \mathrm{C}$, followed by incubation with Dynabeads ${ }^{\circledR}$ protein $\mathrm{G}$ for another $1 \mathrm{~h}$ at room temperature to form the immune complex. Then, the protein samples were loaded onto gels for western blot analysis.

Cell transfection. T84 and SW480 cells ( $3 \times 10^{5}$ cells/well) were seeded into 6-well plates and cultured with antibiotic-free standard growth medium for $24 \mathrm{~h}$ until the confluence reached $60-80 \%$. Subsequently, the cells were infected with the following lentivirus vectors using $7 \mu \mathrm{g} / \mathrm{ml}$ polybrene (Hanbio Biotechnology Co., Ltd.), including RAGE shRNA lentivirus vector (cat. no. sc-36374-SH; Santa Cruz Biotechnology, Inc.), CDC4 shRNA lentivirus vector (sh-CDC4; cat. no. sc-37547-SH; Santa Cruz Biotechnology, Inc.) and the control shRNA plasmid-A (sh-NC; cat. no. sc-108060; Santa Cruz Biotechnology, Inc.). In addition, the RAGE clustered regularly interspaced short palindromic repeats (CRISPR) Activation Plasmid (cat. no. sc-400284-ACT; Santa Cruz Biotechnology, Inc.), and CDC4 CRISPR Activation Plasmid (cat. no. sc-401257-ACT; Santa Cruz Biotechnology, Inc.) were used to upregulate the expression of RAGE (OE-RAGE) and $\mathrm{CDC} 4$ (OE-CDC4) in colon cancer, and were transfected into cells using Lipo3000 (cat. no. L3000008; Thermo Fisher Scientific, Inc.) at $37^{\circ} \mathrm{C}$ for $48 \mathrm{~h}$, in addition to the Control CRISPR/dCas9 Activation Plasmid (OE-NC; cat. no. sc-437275; Santa Cruz Biotechnology, Inc.). Subsequent to $48 \mathrm{~h}$ cell infection/transfection, the mRNA and protein samples 
were extracted from the cells and submitted to RT-qPCR and western blot analysis.

Flow cytometry. T84 and SW480 cells were seeded into 6-well plates and cultured for $24 \mathrm{~h}$. Following different treatments, the cells were gathered into individual centrifuge tubes and suspended in Annexin-binding buffer. Subsequently, the cells were incubated with Annexin V-fluorescein isothiocyanate and propidium iodide solution (BD Biosciences) at room temperature in the shade for $15 \mathrm{~min}$, according to the manufacturer's instructions. The apoptotic percentages of all samples were analyzed using flow cytometry (BD Biosciences). Cell apoptotic rates were analyzed using FlowJo v.10 (FlowJo, LLC).

Animal experiments. The function of scutellarein in inhibiting tumor progression was assessed using a mouse model. A total of 30 male BALB/c nude mice aged 5 weeks old (weight 18-20 g) were obtained from Shanghai SLAC Laboratory Animal Co., Ltd. (Shanghai, China) and maintained under specific pathogen-free conditions at $20-26^{\circ} \mathrm{C}$ with $55 \pm 5 \%$ humidity, a $12 \mathrm{~h}$ light/dark cycle and ad libitum access to food and water. The experiment protocols were ethically approved by the Institutional Animal Care and Use Committee of the Affiliated Hospital of Southwest Medical University (Sichuan, China). The T84 cells $\left(5 \times 10^{6}\right.$ in $200 \mu$ l PBS) were tail-vein injected into the mice to generate a colon cancer-bearing model. Once the tumors had grown, the mice were randomly separated into 3 groups and intraperitoneally injected with scutellarein $(0.5 \mu \mathrm{g} / \mathrm{g}$ body weight) and shRNA-CDC4 $(0.1 \mu \mathrm{g} / \mathrm{g}$ body weight). Mice treated with PBS alone were considered to be the control group. The animal health and behavior, in addition to the tumor sizes, were monitored every 3 days. A total of 20 days later, the mice were euthanized by cervical dislocation and the heads were broken and the tumor weight of each mouse was evaluated. Then, the tumors were removed from the mice and subjected to immunohistochemical staining with an anti-Ki-67 antibody (1:100 dilution; cat. no. 12202; Cell Signaling Technology, Inc.) and hematoxylin (100\%, $3 \mathrm{~min})$ and eosin $(0.5 \%, 30 \mathrm{sec})$ staining at room temperature to assess the effect of scutellarein/CDC4 on the expression of Ki-67 and pathological alteration. The diameter for the maximum tumor was $1.8 \mathrm{~cm}$ and all mice were euthanized at the end of the experiment.

For the immunohistochemical staining, tissue sections were deparaffinized and rehydrated with xylene (100\%) and ethanol $(100,95,80$ and $70 \%)$. Subsequently, the antigens were retrieved using citrate antigen retrieval solution at $95^{\circ} \mathrm{C}$ (Beyotime Institute of Biotechnology) and blocked with $5 \%$ goat serum (AmyJet Scientific, Inc.) diluted in TBS $+0.5 \%$ Tween-20 at room temperature. The sections were probed with the primary antibody against Ki-67 (1:100 dilution; cat. no. 12202; Cell Signaling Technology, Inc.) at $4^{\circ} \mathrm{C}$ overnight. Following the primary antibody incubation, sections were incubated with a HRP-conjugated secondary antibody (1:500; cat. no. 8114; Cell Signaling Technology, Inc.) at room temperature for $30 \mathrm{~min}$, followed by incubation with the chromogen 3,30-diaminobenzidine tetrachloride (R\&D Systems, Inc.) for 2-3 sec at room temperature. Cell nuclei were stained with $1 \%$ Harris hematoxylin solution for $30 \mathrm{sec}$ at room temperature. The protein expression of Ki-67 was evaluated by two pathologists on the base of the positive staining proportion and the staining intensity, as previously described (31). The positive staining percentage was scored as 0 for $\leq 5 \%, 1$ for $6-25 \%, 2$ for $26-50 \%, 3$ for $51-75 \%$ and 4 for $>75 \%$. Intensity was marked as follows: 0 represented no staining, 1 represented weak staining, 2 represented moderate staining and 3 represented strong staining. The final score was obtained by multiplying the percentage score and intensity score.

Statistical analysis. The results are representative of independent experiments, and the data were presented as the mean \pm standard error of the mean. SPSS22.0 statistical software (IBM Corp.) was used to analyze the data between groups with different treatments using paired Student's t-tests for 2 groups and one way analysis of variance followed by a Tukey's test for multiple groups. $\mathrm{P}<0.05$ was considered to indicate a statistically significant difference.

\section{Results}

Scutellarein treatment induces cell apoptosis and inhibits cell viability in CL-40, T84 and SW480 cells. First, the present study investigated the effect of scutellarein treatment on cell apoptosis and viability in colon cancer. The CL-40, T84 and SW480 cells were exposed to gradient concentrations of scutellarein, and the cytotoxic activity of scutellarein was evaluated using an MTT assay. The $\mathrm{IC}_{50}$ values of scutellarein in CL-40, T84 and SW480 cell lines were determined to be 40.9, 40 and $39.6 \mu \mathrm{M}$, respectively (Fig. $1 \mathrm{~A}, \mathrm{C}$ and $\mathrm{E}$ ). In addition, the ratios of cleaved caspase $3 /$ total caspase 3 and cleaved/total caspase 7 were significantly increased when the cells were treated with scutellarein in a dose-dependent manner (Fig. S1A-C), in addition to the apoptosis rates detected using a flow cytometry assay in CL-40, T84 and SW480 cell lines (Fig. 1B, D and F) compared with the control group $(\mathrm{P}<0.05)$. Furthermore, the function of scutellarein treatment in the clone formation ability of CL-40, T84 and SW480 cells was examined using a colony formation assay. As presented in Fig. S1D, compared with the control group, the plates with scutellarein-treated cells demonstrated fewer cell clones, and $\geq 40 \mu \mathrm{M}$ scutellarein induced a significant inhibition in the clone formation ability in a dose-dependent manner compared with the $0 \mu \mathrm{M}$ group $(\mathrm{P}<0.05)$. These results illustrated that scutellarein treatment was able to efficiently inhibit colon cancer cell viability and induce cell apoptosis.

Scutellarein inhibits cell proliferation and promotes cell apoptosis via reducing RAGE expression in T84 and SW480 cells. To reveal the mechanisms underlying scutellarein in colon cancer inhibition, the present study then investigated the effects of scutellarein on the expression of numerous oncoproteins, including CD44, CD50, CD74, CD138, MCAM, CD151, CD166, CD206, RAGE and Madcam1 (14,15). The results revealed that scutellarein treatment $(40 \mu \mathrm{M})$ significantly inhibited the protein expression levels of RAGE compared with the control group $(\mathrm{P}<0.05)$ in T84 (Fig. 2A) and SW480 cells (Fig. 2B), with no significant influence in the protein expression levels of CD44, CD50, CD74, CD138, MCAM, CD151, CD166, CD206 and Madcam1 (P>0.05). However, scutellarein treatment exerted no significant effect on the mRNA levels of 

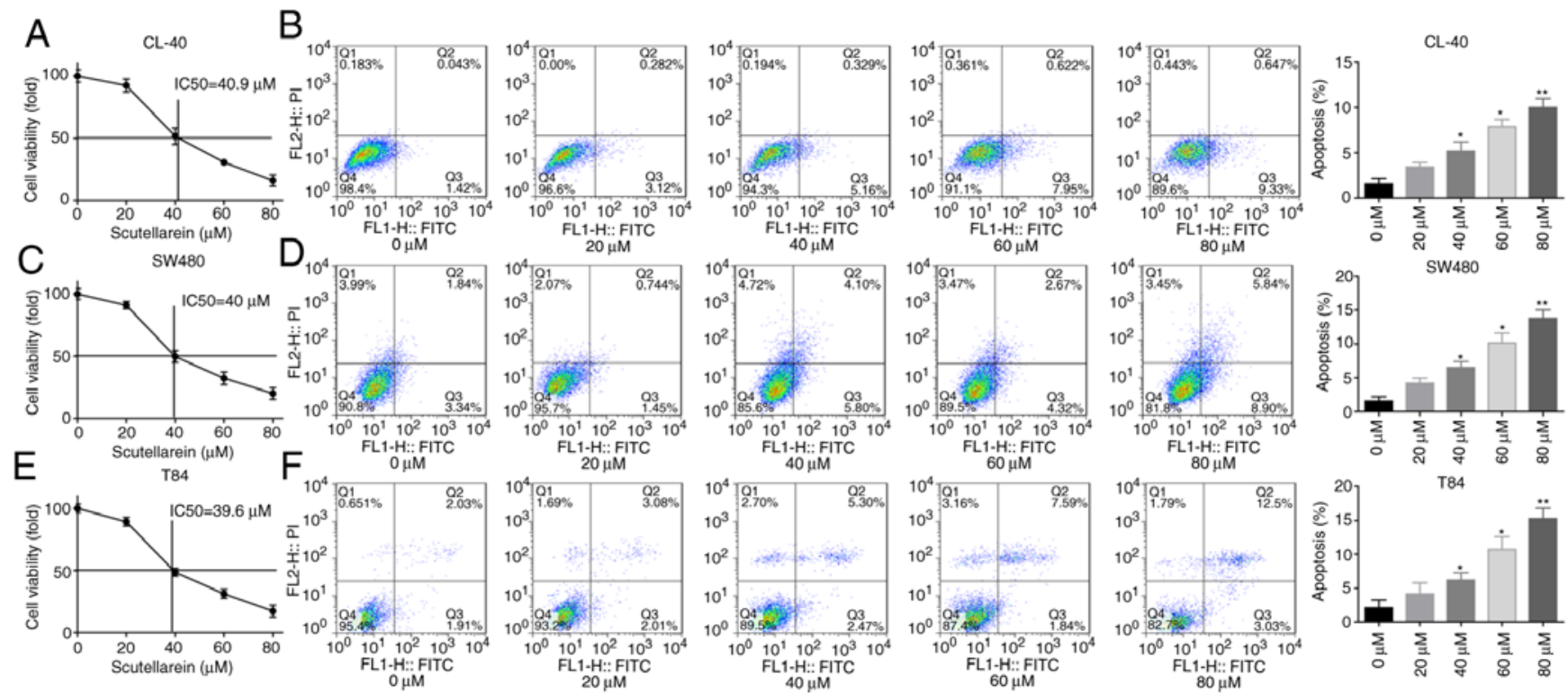

Figure 1. Scutellarein treatment inhibited cell viability and promoted cell apoptosis in colon cancer cells (CL-40, SW480 and T84). The cells were exposed to scutellarein $(0,20,40,60$ and $80 \mu \mathrm{M})$ for $24 \mathrm{~h}$, and then assays were performed. (A) Cytotoxic effect of scutellarein on CL-40 cells were determined using an MTT assay, and the $\mathrm{IC}_{50}$ value was determined to be $40.9 \mu \mathrm{M}$. (B) Effect of scutellarein treatment on the apoptosis rate of CL-40 cells was evaluated by using a flow cytometry assay. (C) Cell viability of SW480 cells was determined using an MTT assay, and the $\mathrm{IC}_{50}$ value was determined to be $40 \mu \mathrm{M}$. (D) $\mathrm{SW}_{480}$ cell apoptosis was detected by using flow cytometry technology. (E) Cytotoxic effect of scutellarein on T84 cells was assessed using an MTT assay, and the $\mathrm{IC}_{50}$ value was determined to be $39.6 \mu \mathrm{M}$. (F) Cell apoptosis in T84 cells was measured using a flow cytometry assay. The data were represented as the mean \pm standard error of the mean $(\mathrm{n}=3)$. ${ }^{*} \mathrm{P}<0.05,{ }^{* *} \mathrm{P}<0.01$ vs. the control group. $\mathrm{IC}_{50}$, half maximal inhibitory concentration.

RAGE compared with the control group ( $\mathrm{P}>0.05$; Fig. 2C). Furthermore, the present study revealed that the significantly increased expression of RAGE induced by OE-RAGE transfection was significantly reduced when T84 and SW480 cells were treated with scutellarein $(40 \mu \mathrm{M} ; \mathrm{P}<0.05$; Fig. 2D). These results demonstrated that scutellarein treatment negatively regulated RAGE expression at the protein level.

To reveal the underlying mechanism of the scutellarein treatment-induced reduction in the RAGE protein expression level, the present study then investigated the effect of scutellarein treatment on the protein stability and ubiquitination of RAGE. The CHX analysis demonstrated that scutellarein treatment significantly reduced the stability of RAGE protein in SW480 ( $\mathrm{P}<0.05$; Fig. 3A) and T84 cell lines compared with the control $(\mathrm{P}<0.05$; Fig. $3 \mathrm{~B})$. In addition, scutellarein treatment significantly enhanced the ubiquitination of the RAGE protein (Fig. 3C). These results revealed that scutellarein treatment may reduce RAGE protein expression via enhancing its ubiquitination and impairing its stability.

The present study then investigated the effects of RAGE in scutellarein-mediated cell proliferation repression and apoptosis promotion in T84 and SW480 cells. The expression levels of RAGE were significantly reduced when the cells were infected with shRNA targeting the RAGE gene at the mRNA and protein levels when compared with the sh-NC group $(\mathrm{P}<0.05$; Fig. 4A and B). As demonstrated in Fig. 4C and D, the overexpression of RAGE significantly blocked the function of scutellarein in promoting the expression levels of cleaved caspase 3/7, while the knockdown of RAGE enhanced the function of scutellarein, with a statistically significant difference compared with the scutellarein-treated group $(\mathrm{P}<0.05$; Fig. 4C and D). Additionally, the proliferation of T84 and SW480 cells in the presence of scutellarein with or without
RAGE overexpression or knockdown was also assessed. Compared with the control group, cell proliferation was significantly repressed following scutellarein treatment, and RAGE overexpression significantly weakened this function while RAGE downregulation enhanced this function in SW480 and T84 cell lines $(\mathrm{P}<0.05$; Fig. $4 \mathrm{E}$ and $\mathrm{F})$. In addition, the present study detected the effect of the scutellarein/RAGE axis on the activation of signals which have been reported to be under the regulation of scutellarein, including nuclear factor- $\kappa \beta(32)$, PKC (33) and VEGF (34). The results revealed that scutellarein treatment significantly decreased the expression levels of p-p65, PKC and VEGF compared with the control group $(\mathrm{P}<0.05)$, whereas the expression levels of $\mathrm{p}-\mathrm{p} 65$ and VEGF were neutralized when RAGE was overexpressed, while RAGE downregulation further decreased p-p65 and VEGF expression levels compared with the scutellarein group ( $\mathrm{P}<0.05$; Fig. S2). However, the deregulation of RAGE exhibited no significant influence in PKC expression in SW480 and T84 cell lines (P>0.05; Fig. S2). These results demonstrated that scutellarein promoted colon cancer cell apoptosis and repressed cell viability via downregulating the expression of RAGE.

Scutellarein increases the combination of CDC4 and RAGE. To investigate the mechanism of the suppressant effects of scutellarein on RAGE levels, the present study detected the expression of a series of ubiquitination-associated proteins, including CDC4, RCHY1, MDM2, CBL and Smurf1 in T84 and SW480 cells using western blot analysis. It was revealed that only the expression levels of CDC4 were significantly increased in presence of scutellarein compared with the control $(\mathrm{P}<0.05)$, with no notable change in the expression levels of RCHY1, MDM2, CBL and Smurf1 (Fig. 5A and C). As CDC4 was considered as one of the ubiquitin ligases, the increase 
A

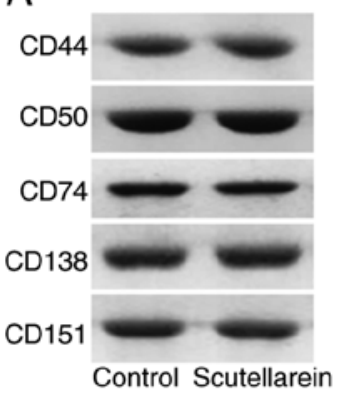

$\mathrm{B}$

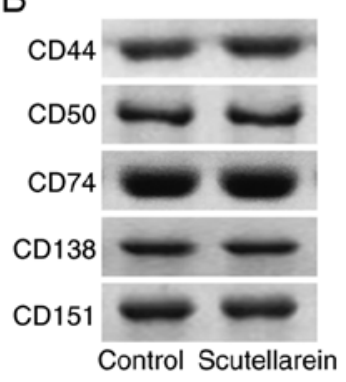

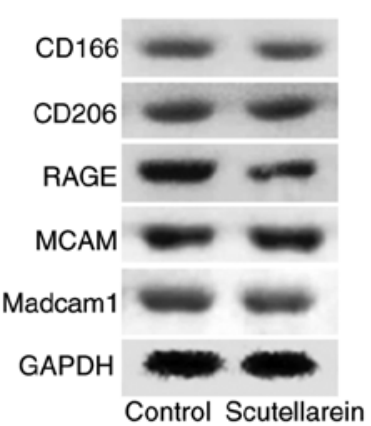

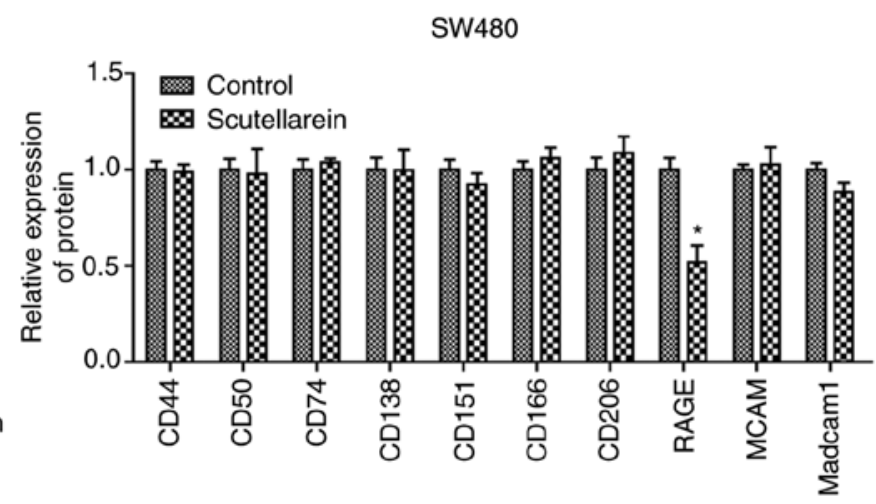

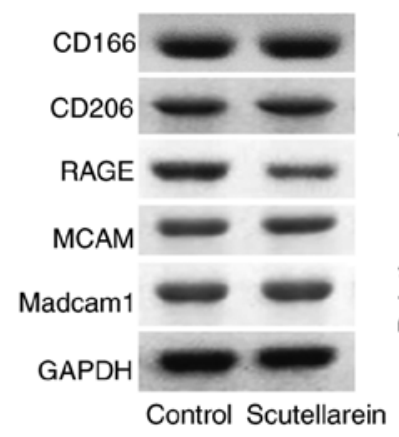
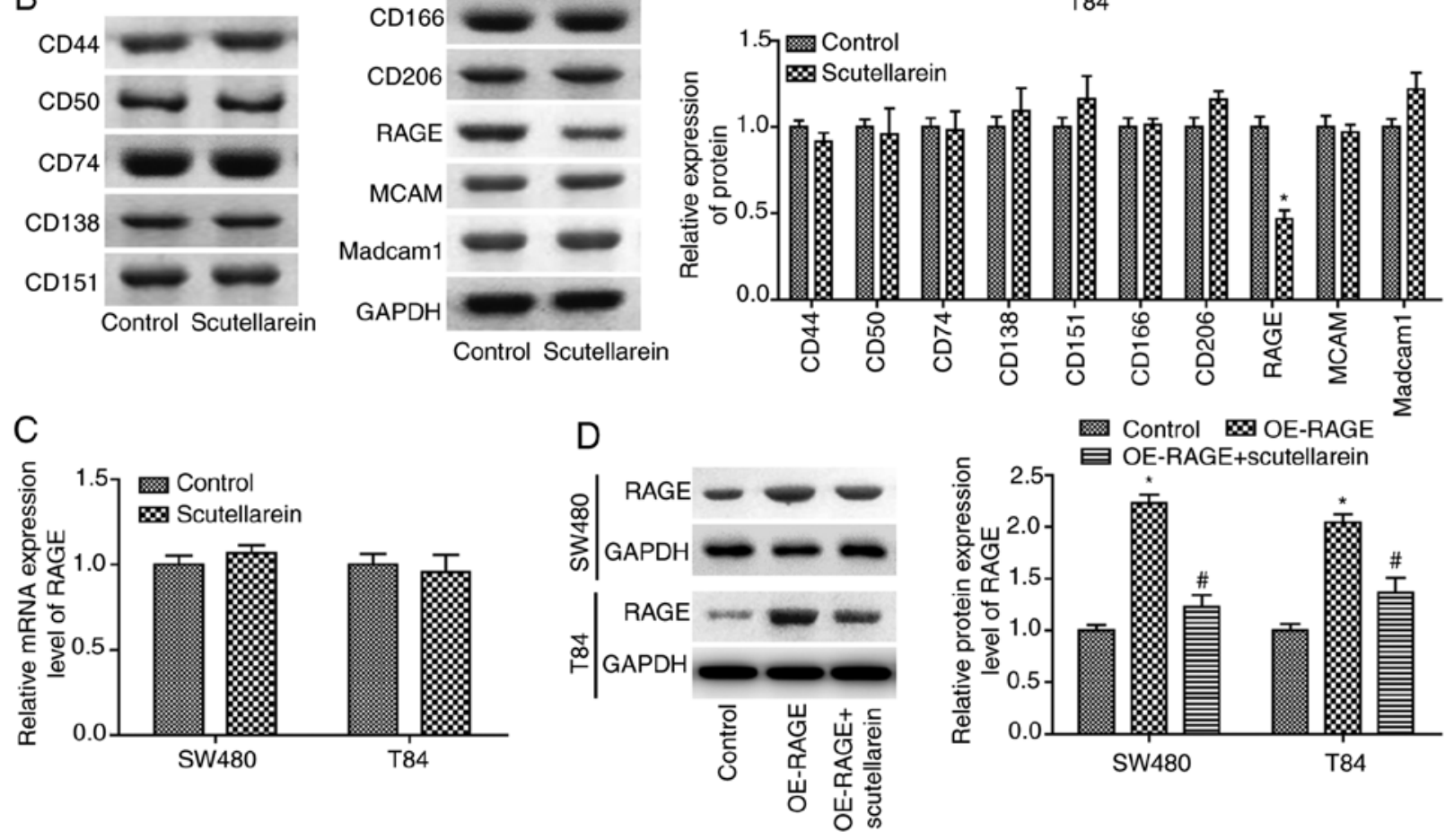

Figure 2. Scutellarein treatment decreased RAGE protein levels in SW480 and T84 cells. Western blot analysis was performed to determine the effects of scutellarein on the expression of CD44, CD50, CD74, CD138, MCAM, CD151, CD166, CD206, RAGE and Madcam1 once the cells were treated with scutellarein (40 $\mu$ M) in (A) SW480 cells and (B) T84 cells, and GAPDH was used as a loading control. (C) mRNA expression levels of RAGE were determined by using a reverse transcription-quantitative PCR assay once the cells were treated with scutellarein $(40 \mu \mathrm{M})$. (D) Western blot analysis was performed to investigate the expression of RAGE protein once cells were transfected with the OE-RAGE plasmid together with scutellarein $(40 \mu \mathrm{M})$ or not. The data demonstrated are representative of three independent experiments. $\mathrm{n}=3$. ${ }^{*} \mathrm{P}<0.05$ vs. the control group; ${ }^{*} \mathrm{P}<0.05$ vs. the OE-RAGE group. CD, cluster of differentiation; MCAM, melanoma cell adhesion molecule; RAGE, receptor for advanced glycation end products; Madcam1, mucosal addressin cell adhesion molecule 1; OE, overexpression.

of CDC4 may have induced the degradation of downstream molecules. IP was performed to investigate the combination of CDC4 and RAGE and the results revealed that scutellarein enhanced the direct or indirect combination of CDC4 and RAGE protein expression in SW480 cells (Fig. 5B) and T84 cells (Fig. 5D). These results indicated that CDC4 may serve a function in the scutellarein-mediated reduction of RAGE expression.

Scutellarein treatment inhibits cell proliferation and promotes cell apoptosis via CDC4-mediated RAGE downregulation. To further study the function CDC4 served in the scutellarein-mediated reduction of RAGE expression and colon cancer inhibition, the present study then performed CHX analysis to investigate the effect of CDC4 on the stability of RAGE. The results demonstrated that the overexpression of $\mathrm{CDC} 4$ signifi- cantly accelerated the degradation of the RAGE protein in SW480 cells (Fig. 6A) and T84 cells (Fig. 6B) compared with the control $(\mathrm{P}<0.05)$. In addition, it was revealed that the overexpression of $\mathrm{CDC} 4$ increased the expression of ubiquitinated RAGE compared with the control (Fig. 6C). Cell proliferation was significantly inhibited $(\mathrm{P}<0.05$; Fig. $6 \mathrm{D}$ and $\mathrm{E})$ while cell apoptosis $(\mathrm{P}<0.05$; Fig. $6 \mathrm{~F})$ was significantly increased when CDC4 was overexpressed in SW480 and T84 cells compared with the control, whereas these effects were significantly abolished when RAGE was overexpressed at the same time $(\mathrm{P}<0.05)$. These results indicated that $\mathrm{CDC} 4$ promoted colon cancer cell apoptosis and inhibited cell proliferation via increasing the RAGE ubiquitination levels.

Furthermore, the present study investigated the function of CDC4 in scutellarein-mediated proliferation inhibition and apoptosis promotion in colon cancer. The expression of CDC4 
A

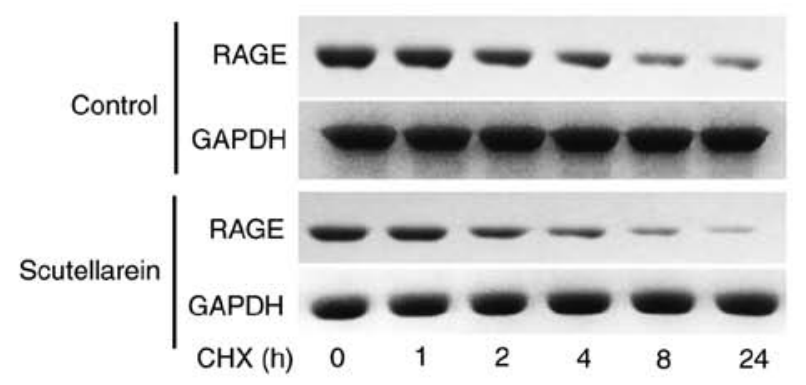

B

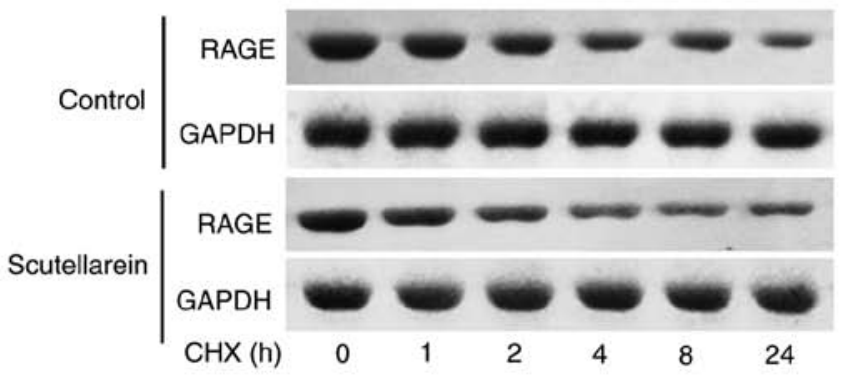

C

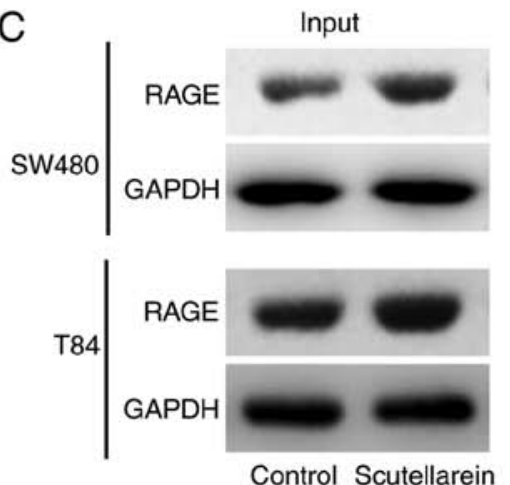

SW480

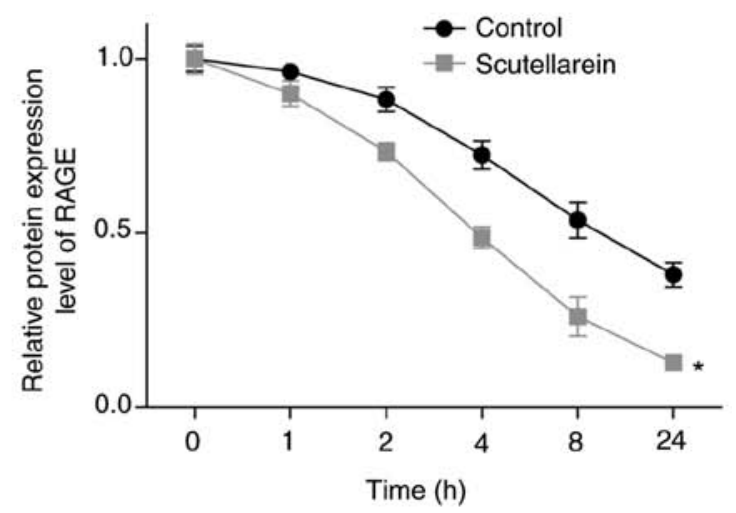

T84
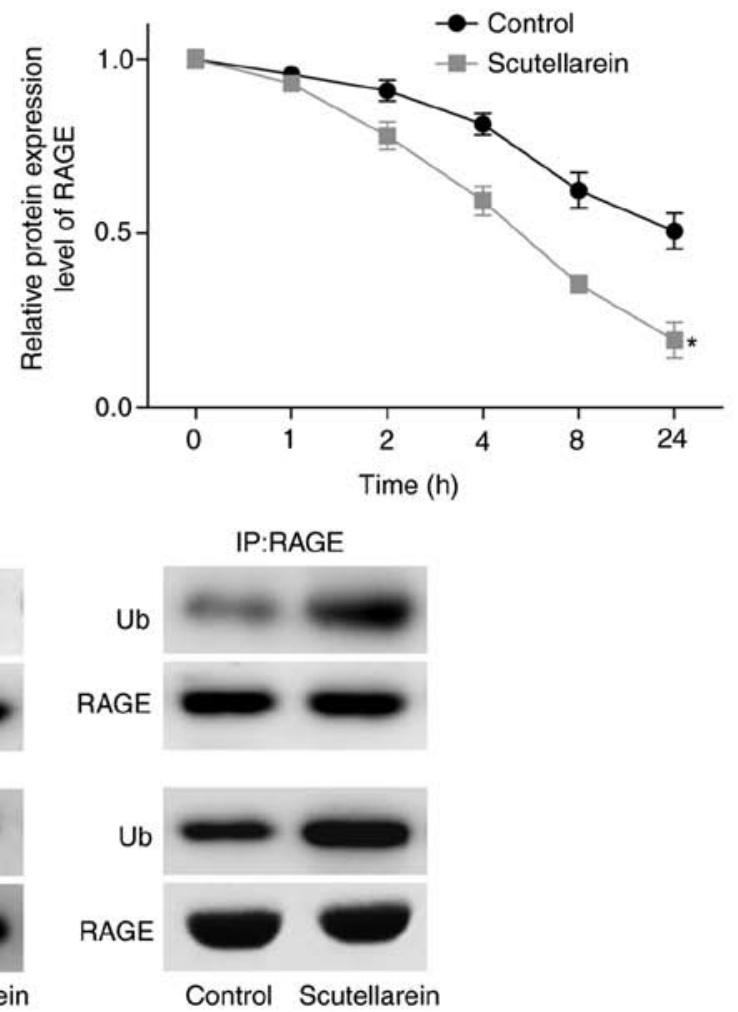

Figure 3. Scutellarein treatment weakened the protein stability of RAGE and increased its ubiquitination. (A) SW480 and (B) T84 cells were exposed to $40 \mu \mathrm{M}$ scutellarein for $24 \mathrm{~h}$, and then the cells were treated with CHX $(100 \mu \mathrm{g} / \mathrm{ml})$ for 1,2, 4, 8 or $24 \mathrm{~h}$, followed by a western blot assay to detect the expression levels of RAGE. (C) An IP assay was used to detect the effect of scutellarein $(40 \mu \mathrm{M})$ treatment on the ubiquitination of the RAGE protein. The data presented are representative of three independent experiments. " $\mathrm{P}<0.05$ vs. the control group. RAGE, receptor for advanced glycation end products; $\mathrm{CHX}$, cycloheximide; IP, immunoprecipitation; Ub, ubiquitin.

was significantly reduced when the cells were infected with sh-CDC4 at the mRNA and protein levels compared with the negative control ( $\mathrm{P}<0.05$; Fig. 7A and B). Knockdown of CDC4 significantly rescued the reduction of RAGE in SW480 and T84 cells mediated by scutellarein treatment $(\mathrm{P}<0.05$; Fig. $7 \mathrm{C})$. CHX analysis revealed that the overexpression of CDC4 significantly enhanced the effect of scutellarein in reducing RAGE stability, while the knockdown of CDC4 significantly weakened the effect of scutellarein $(\mathrm{P}<0.05$; Fig. 7D and $\mathrm{E})$. Furthermore, it was revealed that the increased expression levels of cleaved caspase $3 / 7$ caused by scutellarein treatment were significantly reduced when $\mathrm{CDC} 4$ was downregulated $(\mathrm{P}<0.05$; Fig. 7F and $\mathrm{G})$. In addition, the knockdown of $\mathrm{CDC} 4$ significantly rescued scutellarein-mediated reductions in the expression levels of p-p65 and VEGF $(\mathrm{P}<0.05)$, with no notable change in the expression of PKC ( $>0.05$; Fig. S3). These results demonstrated that the increased level of CDC4 served a vital function in scutellarein-mediated proliferation inhibition and apoptosis promotion in colon cancer.

Scutellarein suppresses the progression of colon cancer via increasing CDC4 expression in vivo. Next, the present study further investigated whether scutellarein inhibited the progression of colon cancer in vivo via upregulating CDC4 expression. A colon cancer-bearing mice model was established by the injection of the colon cancer cell line T84. The solid tumor types were removed and weighed once the mice were sacrificed by cervical dislocation. In comparison with the 
A

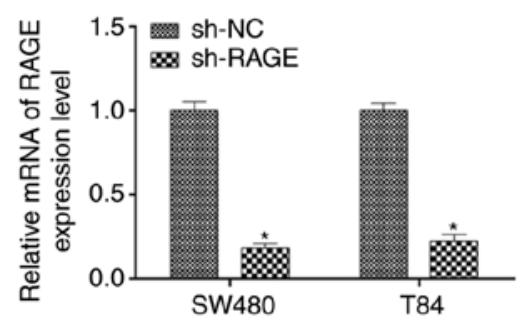

C

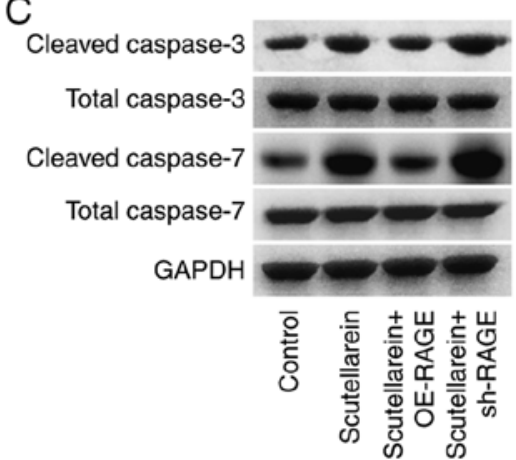

D

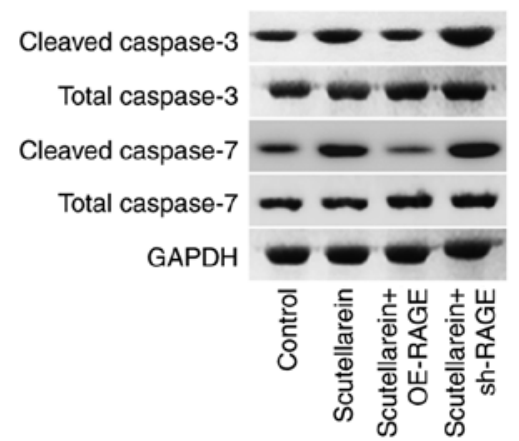

$E$

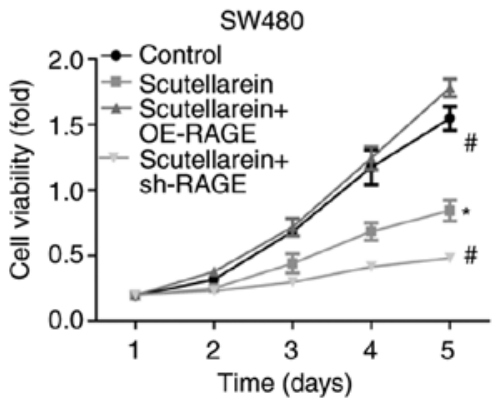

B

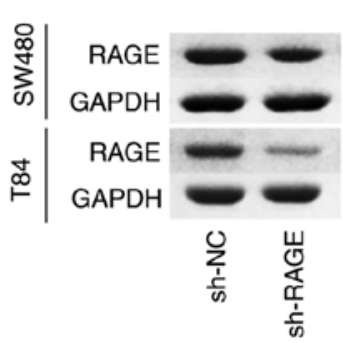

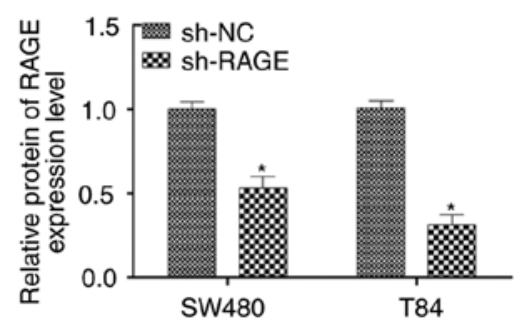

SW480

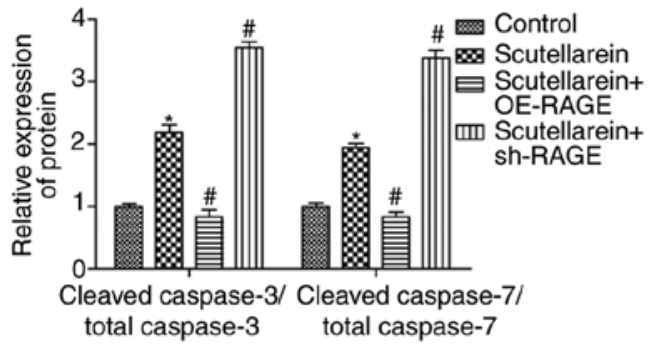

T84

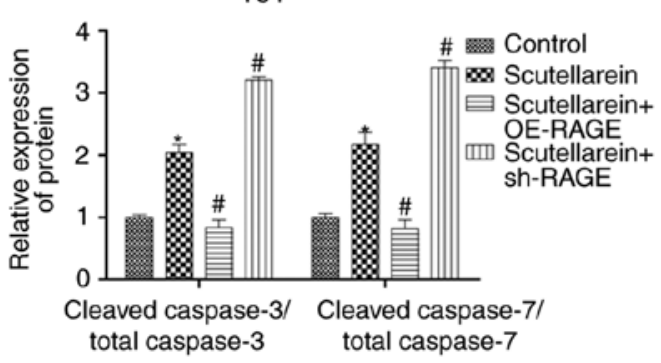

$\mathrm{F}$

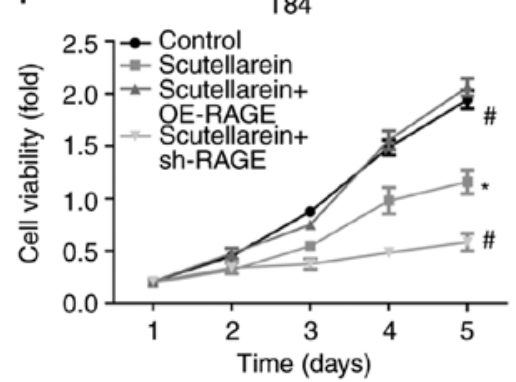

Figure 4. Effects of RAGE on scutellarein-mediated apoptosis promotion and proliferation repression in SW480 and T84 cells. Knockdown efficiency of sh-RAGE was detected using (A) reverse transcription-quantitative PCR and (B) western blot assays in SW480 and T84 cells. Then, the SW480 and T84 cells were treated with scutellarein, scutellarein+OE-RAGE or scutellarein+sh-RAGE. Relative protein levels of cleaved caspase3/7 and total caspase3/7 in (C) SW480 and (D) T84 cells were determined by western blot analysis. Proliferation of (E) SW480 and (F) T84 cells was assessed using an MTT assay. $\mathrm{n}=3$. " $\mathrm{P}<0.05$ vs. the control group; ${ }^{\text {P }}<0.05$ vs. the scutellarein group. RAGE, receptor for advanced glycation end products; sh-, short hairpin RNA; OE, overexpression; $\mathrm{NC}$, negative control.

control group, scutellarein treatment significantly reduced the tumor volume by nearly $50 \%$, while the knockdown of CDC4 significantly increased the tumor volume compared with the scutellarein alone treated group $(\mathrm{P}<0.05$; Fig. $8 \mathrm{~A})$. In addition, the knockdown of CDC4 also significantly neutralized the functions of scutellarein treatment in reducing the expression levels of Ki-67 compared with the control $(\mathrm{P}<0.05$; Fig. 8B) and the alleviation in the histological change of tumor tissues
(Fig. 8C). These results revealed that scutellarein suppressed the in vivo tumor formation of colon cancer via increasing CDC4 expression.

\section{Discussion}

As is well known, colon cancer is one of the most malignant carcinoma types (35). Wild chrysanthemum is the flower head 


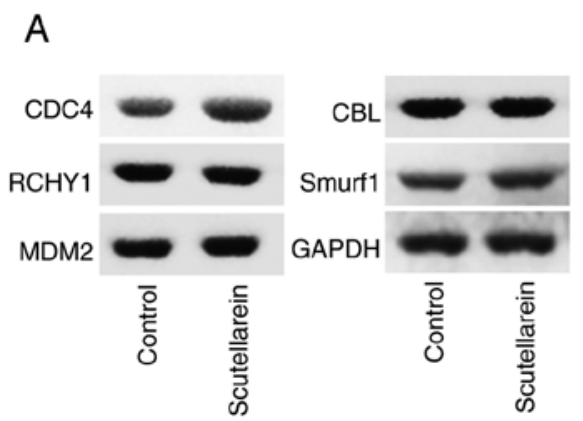

C
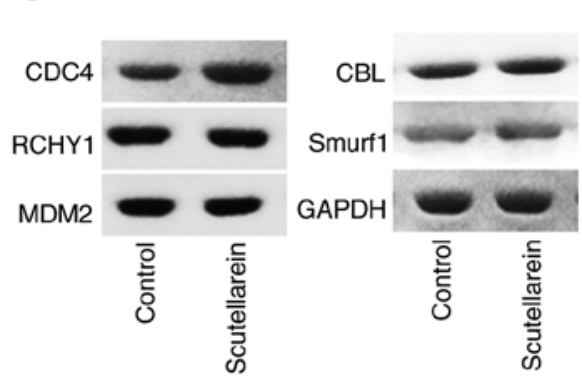

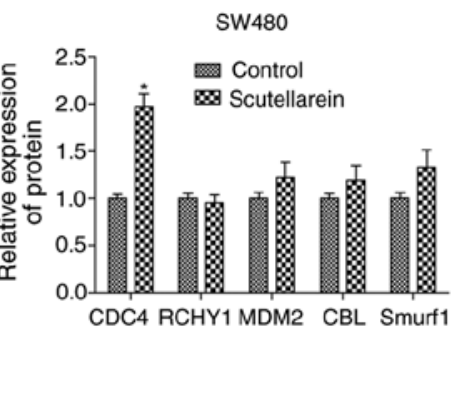

T84

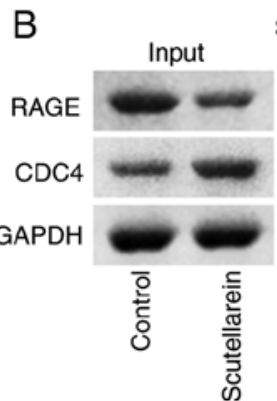

SW480

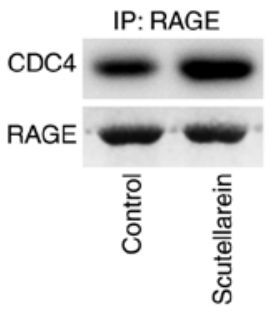

T84

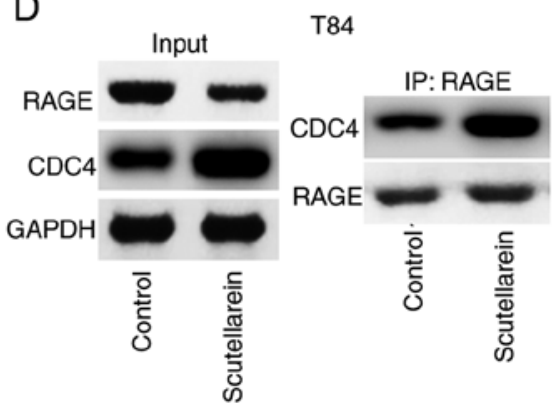

Figure 5. Effects of scutellarein on the combination of CDC4 and RAGE proteins. (A) Western blot analysis was performed to investigate the effects of scutellarein $(40 \mu \mathrm{M})$ on the expression of ubiquitin-associated proteins, including CDC4, RCHY1, MDM2, CBL and Smurf1 in SW480 cells. (B) An IP assay was performed to detect the effects of scutellarein on the combination of CDC4 and RAGE in SW480 cells. (C) Representative data presenting the levels of ubiquitin-associated proteins (CDC4, RCHY1, MDM2, CBL and Smurf1) in T84 cells treated with scutellarein. (D) An IP assay was used to assess the effects of scutellarein on the combination of CDC4 and RAGE proteins in T84 cells. $n=3$. "P<0.05 vs. the control group. RAGE, receptor for advanced glycation end products; CDC4, cell division control protein 4; IP, immunoprecipitation; RCHY1, ring finger and CHY zinc finger domain containing 1; MDM2, MDM2 proto-oncogene; CBL, Cbl proto-oncogene; Smurf1, SMAD specific ubiquitin protein ligase 1.
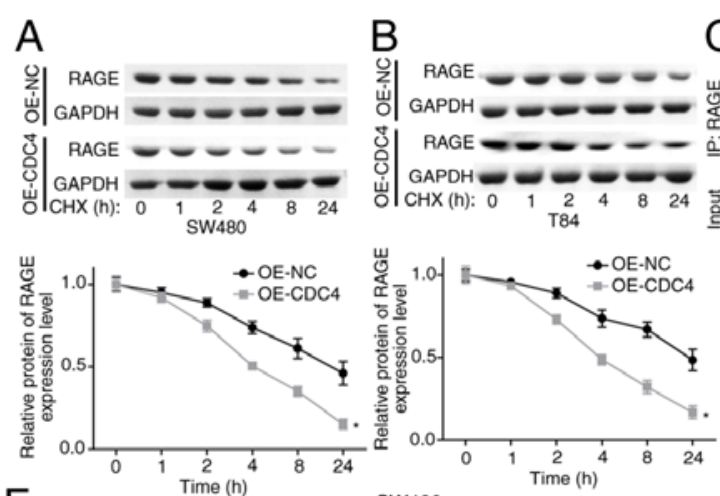

C

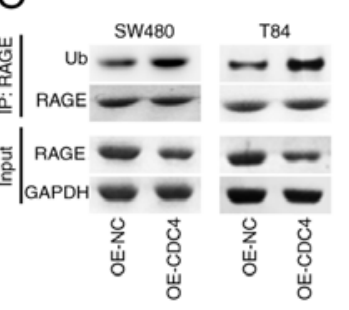

D
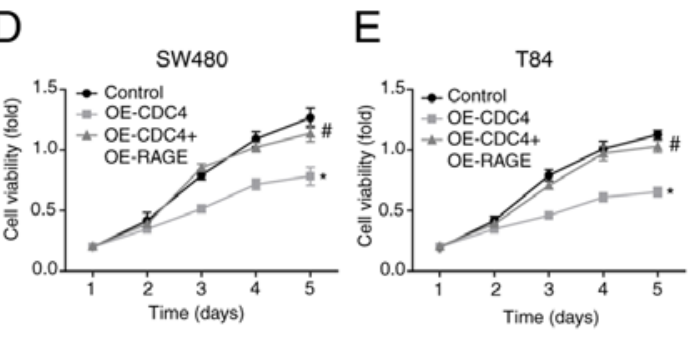

$\mathrm{F}$
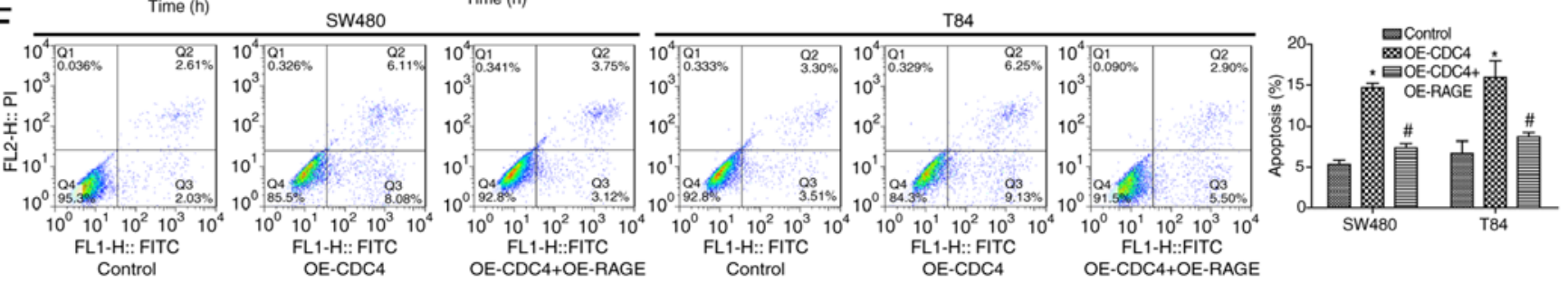

Figure 6. Effects of CDC4/RAGE on the proliferation and apoptosis of SW480 and T84 cells. Following $24 \mathrm{~h}$ of cell transfection with OE-NC or OE-CDC4, (A) SW480 and (B) T84 cells were treated with CHX (100 $\mu \mathrm{g} / \mathrm{ml})$ for 1, 2, 4, 8 or $24 \mathrm{~h}$, and then a western blot assay was performed to detect the protein levels of RAGE. (C) A western blot assay was performed to investigate the ubiquitination of RAGE subsequent to SW480 and T84 cells being transfected with OE-CDC4 or OE-NC. Cell proliferation of (D) SW480 and (E) T84 cells was detected using MTT analysis once the cells were transfected with OE-CDC4, OE-CDC4+OE-PAGE or their negative control vector. (F) Effects of CDC4 and RAGE overexpression on the apoptosis of SW480 and T84 cells were analyzed using flow cytometry. $\mathrm{n}=3 .{ }^{*} \mathrm{P}<0.05$ vs. control group; ${ }^{*} \mathrm{P}<0.05$ vs. the OE-CDC4 group. RAGE, receptor for advanced glycation end products; CDC4, cell division control protein 4; OE, overexpression; NC, negative control; CHX, cycloheximide.

of Chrysanthemum indicum L., which may be obtained wildly in the majority of natural habitats in China $(5,36)$. The present study was designed to investigate the effects and mechanism of scutellarein in the development of colon cancer. The present study demonstrated that scutellarin, derived from wild chrysanthemum, notably inhibited the development of colon cancer 


\section{A}
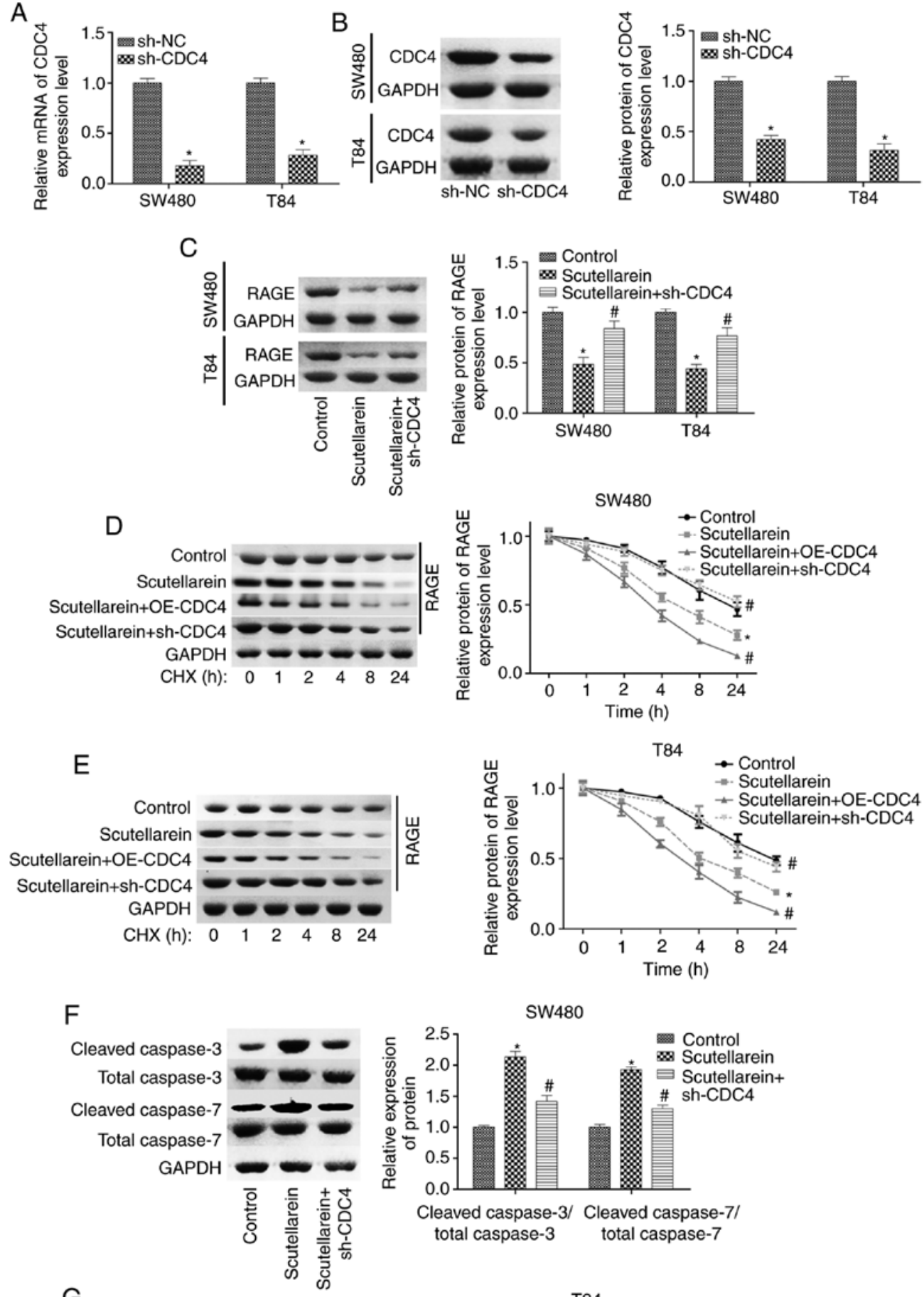

G

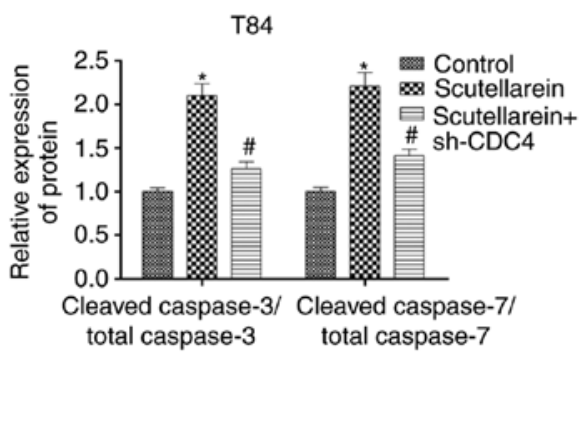

Figure 7. Scutellarein treatment decreased RAGE expression and induced cell apoptosis via increasing CDC4 expression. (A) Reverse transcription-quantitative PCR and (B) western blot assays were used to determine the knockdown efficiency of sh-CDC4 in SW480 and T84 cells. "P<0.05 vs. the sh-NC group. Next, SW480 and T84 cells were divided into three groups (control, scutellarein and scutellarein+sh-CDC4), and then submitted to the following assays. (C) Expression of RAGE was detected using a western blot assay. Protein stability of RAGE was detected by using the CHX reagent together with a western blot assay in (D) SW480 and (E) T84 cells. Levels of cleaved caspase3/7 and total caspase3/7 were determined using a western blot assay in (F) SW480 and (G) T84 cells. " $\mathrm{P}<0.05$ vs. the control group; ${ }^{\text {}} \mathrm{P}<0.05$ vs. the scutellarein group. RAGE, receptor for advanced glycation end products; CDC4, cell division control protein 4; sh-, short hairpin RNA; NC, negative control; CHX, cycloheximide. 
A

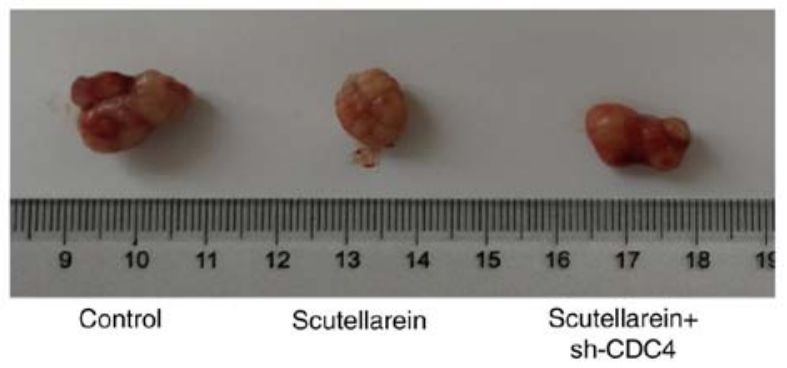

B

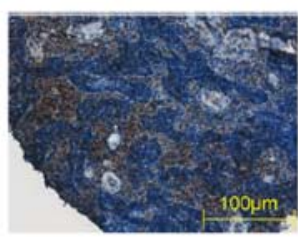

Control

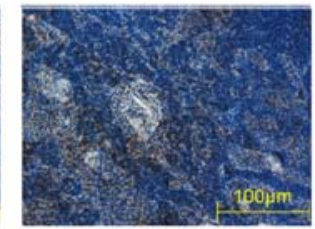

Scutellarein

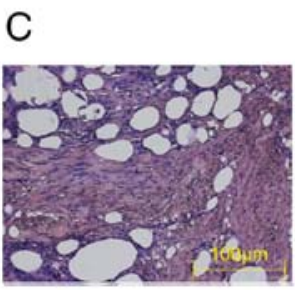

Control

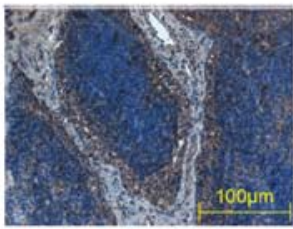

Scutellarein+ sh-CDC4

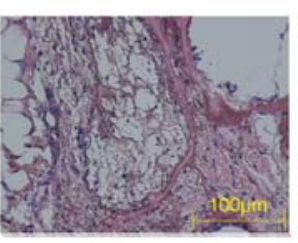

Scutellarein
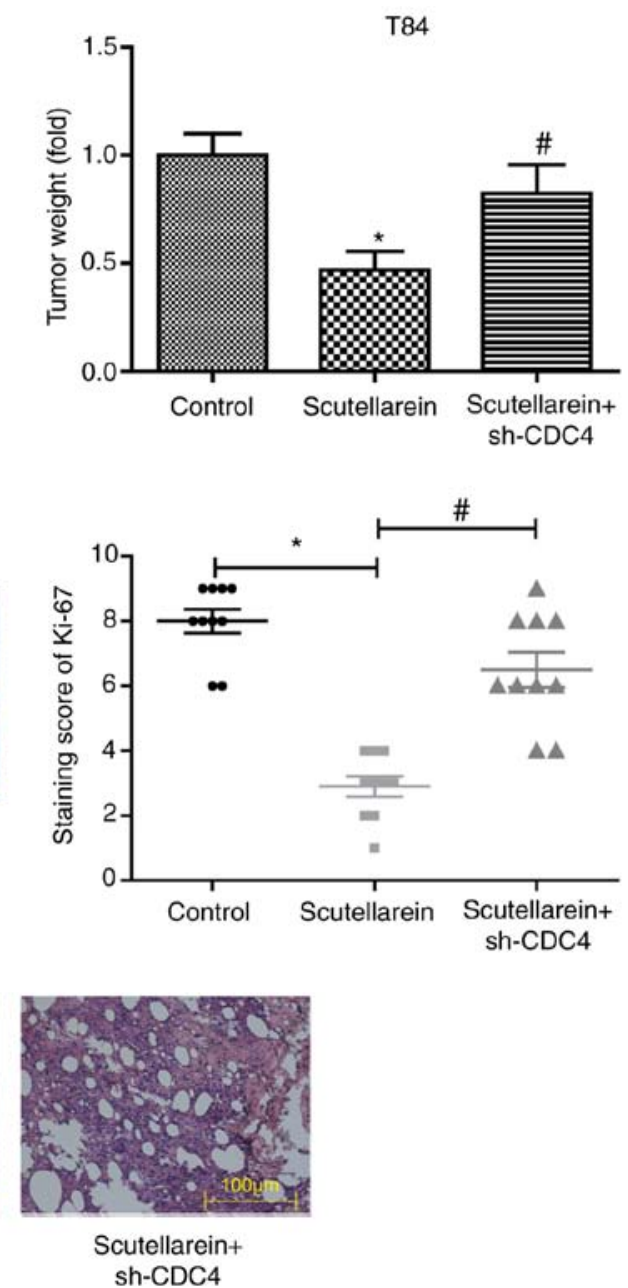

Figure 8. Effects of scutellarein/CDC4 on the tumor growth in a mice xenograft model with a T84 cell injection. (A) Images of tumors removed from the mice treated with scutellarein and scutellarein+sh-CDC4. Bar graph represents the relative weight of the solid tumor types. (B) Immunohistochemical staining was used to detect the expression of $\mathrm{Ki}-67$ in the tumor tissues derived from different groups. (C) Hematoxylin and eosin staining was used to assess the pathological alteration of the tumor tissues derived from different groups. Data are presented as the mean \pm standard error of the mean. $n=10$. ${ }^{*} \mathrm{P}<0.05 \mathrm{vs}$. the control group; ${ }^{\#} \mathrm{P}<0.05$ vs. the scutellarein group. $\mathrm{CDC} 4$, cell division control protein 4 ; sh-, short hairpin RNA.

in vitro and in vivo via CDC4-mediated RAGE ubiquitination enhancement.

As early as 2005, Goh et al (13) reported that the chemically standardized extract from Scutellaria barbata induced a significant increase in the sub G1 phase and promoted cell apoptosis in colon cancer LoVo cells. Subsequently, a study by Wang et al (37) also demonstrated the anti-tumor activity of scutellarein in colon cancer. Recently, Guo et al (12) demonstrated that scutellarein identified from Scutellaria barbata significantly increased the apoptosis of colon cancer HCT116 cells via increasing the production of intracellular reactive oxygen species. As CL-40, T84 and SW480 cell lines are from different types of colon cancer, in that CL-40 cells are derived from the colon adenocarcinoma, T84 cells are derived from the lung metastatic site and SW480 cells are derived from the primary site of colon cancer of Dukes' type B, they were selected for the present study to investigate the effects of scutellarein in the viability and apoptosis of colon cancer cells. Consistent with previous results $(12,13,37)$, the present study also observed that scutellarein treatment significantly inhibited colony formation and cell proliferation and accelerated cell apoptosis in colon cancer CL-20, SW480 and T84 cells $(\mathrm{P}<0.05)$. In addition, it was demonstrated that scutellarein significantly inhibited the in vivo tumor formation ability of T84 cells using colon cancer-bearing mice $(\mathrm{P}<0.05)$. The present results further illustrate the inhibitory function of scutellarein in colon cancer progression.

To investigate the underlying mechanism of scutellarein-mediated repression in colon cancer, the present study investigated the effects of scutellarein treatment on the expression of numerous oncoproteins, including CD44, CD50, CD74, CD138, MCAM, CD151, CD166, CD206, RAGE and Madcam1. As CL-40 and SW480 are primary cell lines of colon cancer, one was selected (SW480) together with T84 (a metastasis cell line) for the subsequent experiments. The present results demonstrate that scutellarein treatment significantly inhibited the expression of RAGE compared with the control $(\mathrm{P}<0.05)$, with no substantial influence in the expression levels of CD44, CD50, CD74, CD138, MCAM, CD151, CD166, CD206 and Madcam1. An increasing number of studies have demonstrated the importance of RAGE in the pathogenesis of multiple human disease types, including cancer (38-41). The deregulation of RAGE is considered to be an important factor in tumorigenesis, and the increase of RAGE is associated 


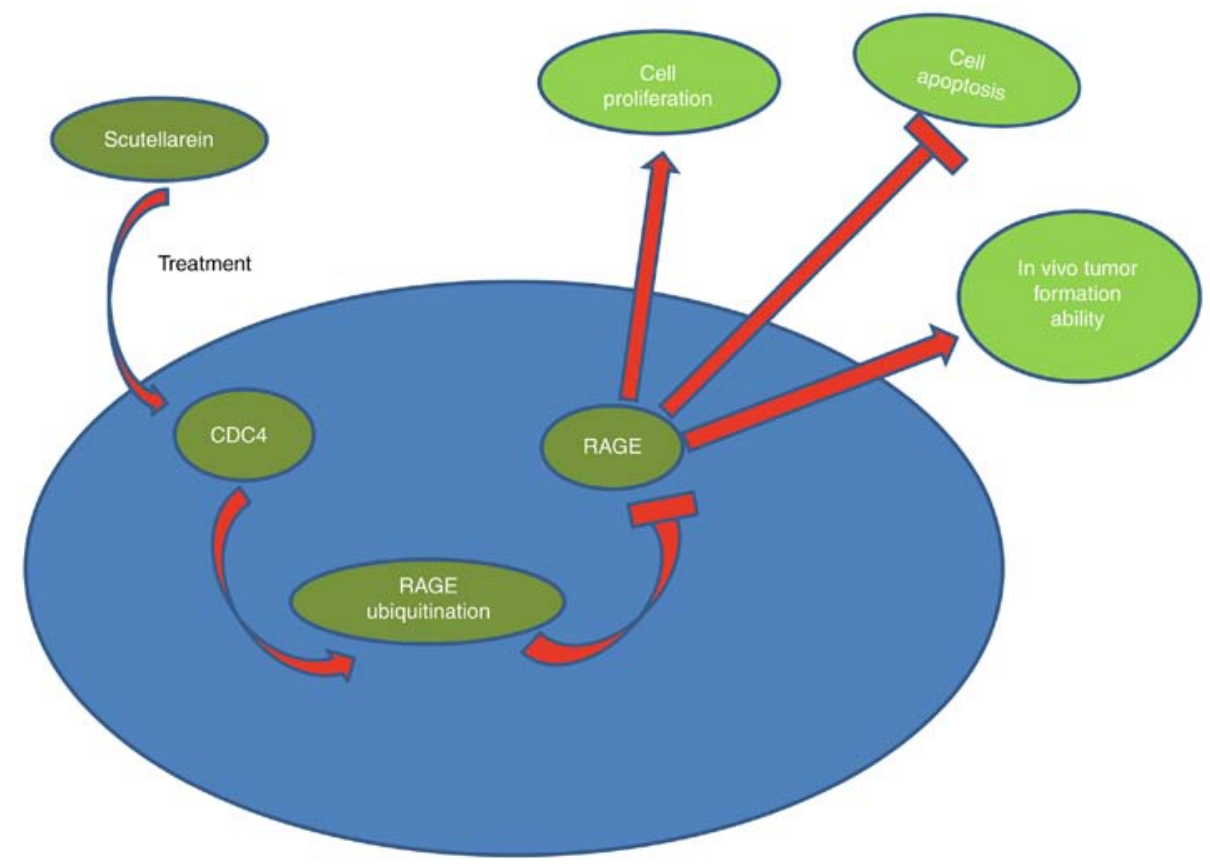

Figure 9. Schematic diagram of the anti-tumor function of scutellarein in colon cancer. Scutellarein treatment reduced the expression of RAGE via the CDC4-mediated ubiquitination degradation pathway, which then inhibited cell proliferation, tumorigenesis and induced cell apoptosis in colon cancer. RAGE, receptor for advanced glycation end products; $\mathrm{CDC} 4$, cell division control protein 4.

with a diverse range of malignancies $(22,42)$. In the present study, the results demonstrated that scutellarein treatment significantly decreased the protein levels of RAGE, but not the mRNA levels, compared with the control $(\mathrm{P}<0.05)$. Thus, the present study investigated the effect of scutellarein on RAGE protein stability and ubiquitination, and the results revealed that scutellarein treatment decreased the protein stability of RAGE and enhanced its ubiquitination. Similarly, RAGE was also reported to be regulated by the ubiquitination-degradation pathway by the ubiquitin E3 ligase subunit F-box protein O10 (43). Furthermore, the present study observed that the overexpression of RAGE weakened while the knockdown of RAGE enhanced scutellarein functions in promoting cell apoptosis and inhibiting cell proliferation in colon cancer, suggesting that scutellarein inhibited colon cancer progression via downregulating RAGE.

Ubiquitination is a process in which ubiquitin alters and specifically modifies the target proteins with the help of a series of particular enzymes, including ubiquitin activating enzyme, ubiquitin conjugating enzyme and ubiquitin ligase (44). An increasing number of studies have demonstrated that ubiquitination is strongly implicated in the pathogenesis of carcinogenesis $(45,46)$. In the present study, the underlying mechanism of the scutellarein-mediated ubiquitination of RAGE protein was examined. An increase in CDC4 expression was observed in the presence of scutellarein. CDC4/F-box and WD repeat domain containing 7, located on the $4 \mathrm{q}$, is considered to be a vital anti-oncogene in various cancer types, in addition to a potential therapeutic target, with mutations observed in pancreatic, colorectal and ovarian tumor types (47). The results of the present study confirmed that CDC4 may combine with the RAGE protein and then induce its ubiquitination and the subsequent degradation. Furthermore, a significant decrease in cell proliferation and an increase in cell apoptosis rates were observed in SW480 and T84 cells with CDC4 overexpression compared with the control $(\mathrm{P}<0.05)$, while this effect was impaired when RAGE was downregulated, suggesting that $\mathrm{CDC} 4$ inhibited colon cancer progression via decreasing the expression of RAGE. Furthermore, the present results also revealed the important function of CDC4 in scutellarein-mediated increases in cell apoptosis and inhibition in cell proliferation and tumorigenesis in colon cancer.

However, there are a number of limitations to the present study. In the present study it was mainly revealed that scutellarein inhibited the expression of the oncoprotein RAGE via increasing CDC4-mediated ubiquitination enhancement, which then inhibited cell proliferation and induced cell apoptosis. However, the present study did not investigate the molecular mechanism underlying the scutellarein-mediated CDC4 upregulation. In addition, the results revealed that scutellarein inhibited cell proliferation and induced cell apoptosis in T84 and SW480 cells in a similar manner. However, T84 cells are derived from a lung metastatic site, while SW480 cells are derived from a primary site of colon cancer of Dukes' type B, indicating that these are two different types of cells with different malignant behaviors. It was hypothesized that this may be induced by the same protein which is located at the upstream of $\mathrm{CDC} 4$, but this was not further investigated. These will be investigated in future studies through performing sequencing to determine the gene which is modulated by scutellarein in T84 and SW480 cell lines. Furthermore, the present study did not examine the effect of scutellarein on the function of CL-40 cells due to the limitations in funding and time. The present study only examined the effects and underlying mechanisms of scutellarein, an active ingredient of wild chrysanthemum, on the progression of colon cancer. However, it is not clear whether chamomile and other chrysanthemums 
have similar effects. In future studies, the effects of chamomile and other chrysanthemums on colon cancer progression will be examined.

In conclusion, the present investigation revealed that scutellarein derived from wild chrysanthemum may effectively suppress the proliferation and tumorigenesis and induce the apoptosis of colon cancer cells through downregulating RAGE expression mediated by CDC4 upregulation (Fig. 9). The present results may provide more useful information for the application of scutellarein in the treatment of colon cancer.

\section{Acknowledgements}

Not applicable.

\section{Funding}

The present study was supported by a research grant for Doctors of the Affiliated Hospital of Southwest Medical University and Luzhou People's Government-Southwest Medical University Cooperative Scientific Research Project (grant no. 2019LZXNDJ26).

\section{Availability of data and materials}

All data generated or analyzed during this study are included in this published article.

\section{Authors' contributions}

YL and JW provided the idea and performed the experiments, in addition to writing the manuscript. SZ and JL performed the data analyses and parts of the experiments. WD performed parts of the data analyses. YL revised the manuscript. All authors read and approved the final manuscript.

\section{Ethics approval and consent to participate}

Athymic nude mouse assays were performed in accordance with the institutional principles for the concern and use of animals and the protocol was ethically approved by the ethical committee of the Affiliated Hospital of Southwest Medical University.

\section{Patient consent for publication}

Not applicable.

\section{Competing interests}

The authors declare that they have no competing interests.

\section{References}

1. Labianca R, Beretta GD, Kildani B, Milesi L, Merlin F, Mosconi S, Pessi MA, Prochilo T, Quadri A, Gatta G, et al: Colon cancer. Crit Rev Oncol Hematol 74: 106-133, 2010.

2. Freeman HJ: Early stage colon cancer. World J Gastroenterol 19: 8468-8473, 2013.

3. Orangio GR: The economics of colon cancer. Surg Oncol Clin N Am 27: 327-347, 2018.
4. Zhang Y, Shi J, Huang H, Ren J, Li N and Dai M: Burden of colorectal cancer in China. Zhonghua Liu Xing Bing Xue Za Zhi 36: 709-714, 2015 (In Chinese).

5. Sun S, Jiang P, Su W, Xiang Y, Li J, Zeng L and Yang S: Wild chrysanthemum extract prevents UVB radiation-induced acute cell death and photoaging. Cytotechnology 68: 229-240, 2016.

6. Yang WS, Kim D, Yi YS, Kim JH, Jeong HY, Hwang K, Kim JH, Park J and Cho JY: AKT-targeted anti-inflammatory activity of the methanol extract of Chrysanthemum indicum var. albescens. J Ethnopharmacol 201: 82-90, 2017.

7. Deng Y, Jiang J, Chen S, Teng N, Song A, Guan Z, Fang W and Chen F: Combination of multiple resistance traits from wild relative species in Chrysanthemum via trigeneric hybridization. PLoS One 7: 30, 2012

8. Hassanpouraghdam MB: Flowerhead volatile oil composition of soilless culture-grown Chrysanthemum balsamita L. Nat Prod Res 23: 672-677, 2009.

9. Shi X, Chen G, Liu X, Qiu Y, Yang S, Zhang Y, Fang X, Zhang C and Liu X: Scutellarein inhibits cancer cell metastasis in vitro and attenuates the development of fibrosarcoma in vivo. Int $\mathrm{J}$ Mol Med 35: 31-38, 2015

10. Cheng CY, Hu CC, Yang HJ, Lee MC and Kao ES: Inhibitory effects of scutellarein on proliferation of human lung cancer A549 cells through ERK and NFkB mediated by the EGFR pathway. Chin J Physiol 57: 182-187, 2014.

11. Parajuli P, Joshee N, Rimando AM, Mittal S and Yadav AK: In vitro antitumor mechanisms of various Scutellaria extracts and constituent flavonoids. Planta Med 75: 41-48, 2009.

12. Guo F, Yang F and Zhu YH: Scutellarein from Scutellaria barbate induces apoptosis of human colon cancer HCT116 cells through the ROS-mediated mitochondria-dependent pathway. Nat Prod Res 33: 2372-2375, 2019.

13. Goh D, Lee YH and Ong ES: Inhibitory effects of a chemically standardized extract from Scutellaria barbata in human colon cancer cell lines, LoVo. J Agric Food Chem 53: 8197-8204, 2005.

14. Behzad MM, Asnafi AA, Jaseb K, Jalali Far MA and Saki N: Expression of CD markers' in immune thrombocytopenic purpura: Prognostic approaches. APMIS 125: 1042-1055, 2017.

15. Bacher P and Scheffold A: Flow-cytometric analysis of rare antigen-specific T cells. Cytometry A 83: 692-701, 2013.

16. Tripathi SC, Fahrmann JF, Celiktas M, Aguilar M, Marini KD, Jolly MK, Katayama H, Wang H, Murage EN, Dennison JB, et al: MCAM mediates chemoresistance in small-cell lung cancer via the PI3K/AKT/SOX2 signaling pathway. Cancer Res 77 : 4414-4425, 2017.

17. Wang $\mathrm{Z}$ and Yan X: CD146, a multi-functional molecule beyond adhesion. Cancer Lett 330: 150-162, 2013.

18. Zhang H, Zhang J, Wang Z, Lu D, Feng J, Yang D, Chen X and Yan X: CD146 is a potential marker for the diagnosis of malignancy in cervical and endometrial cancer. Oncol Lett 5: 1189-1194, 2013.

19. Tanida S, Mizoshita T, Mizushima T, Sasaki M, Shimura T, Kamiya T, Kataoka $\mathrm{H}$ and Joh T: Involvement of oxidative stress and mucosal addressin cell adhesion molecule-1 (MAdCAM-1) in inflammatory bowel disease. J Clin Biochem Nutr 48: 112-116, 2011.

20. Truffi M, Colombo M, Peñaranda-Avila J, Sorrentino L, Colombo F, Monieri M, Collico V, Zerbi P, Longhi E, Allevi R, et al: Nano-targeting of mucosal addressin cell adhesion molecule-1 identifies bowel inflammation foci in murine model. Nanomedicine (Lond) 12: 1547-1560, 2017.

21. Logsdon CD, Fuentes MK, Huang EH and Arumugam T: RAGE and RAGE ligands in cancer. Curr Mol Med 7: 777-789, 2007.

22. Palanissami G and Paul SFD: RAGE and Its ligands: Molecular interplay between glycation, inflammation, and hallmarks of cancer-a review. Horm Cancer 9: 295-325, 2018.

23. Fuentes MK, Nigavekar SS, Arumugam T, Logsdon CD, Schmidt AM, Park JC and Huang EH: RAGE activation by S100P in colon cancer stimulates growth, migration, and cell signaling pathways. Dis Colon Rectum 50: 1230-1240, 2007.

24. Foot N, Henshall T and Kumar S: Ubiquitination and the regulation of membrane proteins. Physiol Rev 97: 253-281, 2017.

25. Swatek KN and Komander D: Ubiquitin modifications. Cell Res 26: 399-422, 2016.

26. Zhou MJ, Chen FZ and Chen HC: Ubiquitination involved enzymes and cancer. Med Oncol 31: 93, 2014.

27. Jin X, Yang C, Fan P, Xiao J, Zhang W, Zhan S, Liu T, Wang D and $\mathrm{Wu} \mathrm{H}$ : CDK5/FBW7-dependent ubiquitination and degradation of EZH2 inhibits pancreatic cancer cell migration and invasion. J Biol Chem 292: 6269-6280, 2017. 
28. Gallo LH, Ko J and Donoghue DJ: The importance of regulatory ubiquitination in cancer and metastasis. Cell Cycle 16: 634-648, 2017.

29. Yan C, Su H, Song X, Cao H, Kong L and Cui W: Smad ubiquitination regulatory factor 1 (Smurf1) promotes thyroid cancer cell proliferation and migration via ubiquitin-dependent degradation of kisspeptin-1. Cell Physiol Biochem 49: 2047-2059, 2018.

30. Livak KJ and Schmittgen TD: Analysis of relative gene expression data using real-time quantitative PCR and the 2(-Delta Delta $\mathrm{C}(\mathrm{T})$ ) method. Methods 25: 402-408, 2001.

31. Xin B, He X, Wang J, Cai J, Wei W, Zhang T and Shen X: Nerve growth factor regulates CD133 function to promote tumor cell migration and invasion via activating ERK1/2 signaling in pancreatic cancer. Pancreatology 16: 1005-1014, 2016.

32. Huang XW, Xu Y, Sui X, Lin H, Xu JM, Han D, Ye DD, Lv GF, Liu YX, Qu XB and Duan MH: Scutellarein suppresses $\mathrm{A} \beta$-induced memory impairment via inhibition of the NF- $\mathrm{B}$ pathway in vivo and in vitro. Oncol Lett 17: 5581-5589, 2019.

33. Tian X, Chang L, Ma G, Wang T, Lv M, Wang Z, Chen L, Wang Y, Gao X and Zhu Y: Delineation of platelet activation pathway of scutellarein revealed its intracellular target as protein kinase C. Biol Pharm Bull 39: 181-191, 2016.

34. Thirusangu P, Vigneshwaran V, Vijay Avin BR, Rakesh $\mathrm{H}$, Vikas HM and Prabhakar BT: Scutellarein antagonizes the tumorigenesis by modulating cytokine VEGF mediated neoangiogenesis and DFF-40 actuated nucleosomal degradation. Biochem Biophys Res Commun 484: 85-92, 2017.

35. Labianca R, Nordlinger B, Beretta GD, Mosconi S, Mandalà M, Cervantes A and Arnold D; ESMO Guidelines Working Group: Early colon cancer: ESMO clinical practice guidelines for diagnosis, treatment and follow-up. Ann Oncol 24 (Suppl 6): vi64-vi72, 2013

36. Bosman FT and Yan P: Molecular pathology of colon cancer. Pol J Pathol 65 (4 Suppl 1): S1-S11, 2014 (In Polish).

37. Wang F, Yang B, Zhao Y, Liao X, Gao C, Jiang R, Han B, Yang J, Liu M and Zhou R: Host-guest inclusion system of scutellarein with 2-hydroxypropyl-beta-cyclodextrin: Preparation, characterization, and anticancer activity. J Biomater Sci Polym Ed 25 594-607, 2014
38. van Zoelen MA, Achouiti A and van der Poll T: RAGE during infectious diseases. Front Biosci (Schol Ed) 3: 1119-1132, 2011.

39. Lee TW, Kao YH, Chen YJ, Chao TF and Lee TI: Therapeutic potential of vitamin D in AGE/RAGE-related cardiovascular diseases. Cell Mol Life Sci 76: 4103-4115, 2019.

40. Azizan N, Suter MA, Liu Y and Logsdon CD: RAGE maintains high levels of $\mathrm{NF \kappa B}$ and oncogenic Kras activity in pancreatic cancer. Biochem Biophys Res Commun 493: 592-597, 2017.

41. Rahimi F, Karimi J, Goodarzi MT, Saidijam M, Khodadadi I, Razavi AN and Nankali M: Overexpression of receptor for advanced glycation end products (RAGE) in ovarian cancer. Cancer Biomark 18: 61-68, 2017.

42. Tesarova P,Cabinakova M,Mikulova V,Zima T and Kalousova M: RAGE and its ligands in cancer-culprits, biomarkers, or therapeutic targets? Neoplasma 62: 353-364, 2015

43. Evankovich J, Lear T, McKelvey A, Dunn S, Londino J, Liu Y, Chen BB and Mallampalli RK: Receptor for advanced glycation end products is targeted by FBXO10 for ubiquitination and degradation. FASEB J 31: 3894-3903, 2017.

44. Rittinger K and Ikeda F: Linear ubiquitin chains: Enzymes, mechanisms and biology. Open Biol 7: pii: 170026, 2017.

45. Ao N, Chen Q and Liu G: The small molecules targeting ubiquitin-proteasome system for cancer therapy. Comb Chem High Throughput Screen 20: 403-413, 2017.

46. Ding F, Xiao H, Wang M, Xie X and Hu F: The role of the ubiquitin-proteasome pathway in cancer development and treatment Front Biosci (Landmark Ed) 19: 886-895, 2014.

47. Davis $\mathrm{H}$ and Tomlinson I: CDC4/FBXW7 and the 'just enough' model of tumourigenesis. J Pathol 227: 131-135, 2012.

(i) $\Theta$ This work is licensed under a Creative Commons Attribution-NonCommercial-NoDerivatives 4.0 International (CC BY-NC-ND 4.0) License. 